Research article

\title{
Controlled release tablets based on HPMC:lactose blends
}

E. Moussa, ${ }^{1}$ F. Siepmann, ${ }^{1}$ M.P. Flament,${ }^{1}$ Y. Benzine, ${ }^{1}$ F. Penz,${ }^{2}$ J. Siepmann,,${ }^{1,}$ Y. Karrout ${ }^{1}$

${ }^{1}$ Univ. Lille, Inserm, CHU Lille, U1008, F-59000 Lille, France

${ }^{2}$ Meggle, BG Excipients \& Technology, Megglestr. 6-12, 83512 Wasserburg, Germany

*correspondence:

Prof. Juergen Siepmann

University of Lille, College of Pharmacy

Inserm U1008

3 rue du Professeur Laguesse

59006 Lille, France

juergen.siepmann@univ-lille.fr 


\begin{abstract}
Hydroxypropyl methylcellulose (HPMC) is a frequently used matrix former for controlled release tablets. To adjust desired drug release kinetics, freely water-soluble lactose can be added. The aim of this study was to investigate the importance of the type of preparation technique of propranolol $\mathrm{HCl}$ loaded matrix tablets based on such HPMC:lactose blends. The tablets were prepared by: (i) direct compression of physical blends of drug, HPMC and lactose, (ii) direct compression of blends of the drug and co-processed HPMC:lactose (spray agglomerated), and (iii) via wet granulation. Interestingly, the co-processed HPMC:lactose particles provided better flowability and compactability than the physical HPMC:lactose blends, while the resulting water uptake kinetics and drug release rates were similar. Also wet granulation led to similar drug release kinetics. Thus, the use of co-processed HPMC:lactose can offer interesting technical advantages for the manufacturing of controlled release matrix tablets, while system performance remains unaltered.
\end{abstract}

Keywords: HPMC; tablet; lactose; direct compression; controlled release 


\section{Introduction}

Hydrophilic matrix tablets offer an interesting potential for oral controlled drug delivery $[1,2,3,4,5,6,7]$. Hydroxypropyl methylcellulose (HPMC) is frequently used for this purpose $[8,9,10,11,12,13,14]$. Upon administration, water penetrates into the system and dissolves the drug $[15,16,17]$. The resulting drug concentration gradients (inside - outside the tablet) are the driving forces for drug release [18,19,20,21]. Furthermore, HPMC substantially swells upon contact with water $[22,23,24,25,26]$ : This results in increasing drug mobility (accelerating drug release), but also in increasing diffusion pathway lengths to be overcome (slowing down drug release) $[27,28,29,30]$. Depending on the initial drug loading and drug solubility, also limited drug solubility effects can be of importance: If the amount of water penetrating into the tablet is not sufficient to dissolve the entire drug amount, dissolved and non-dissolved drug co-exist in the system [31]. Importantly, only dissolved drug is available for diffusion. Dissolved drug molecules/ions that diffuse out of the system are replaced by the partial dissolution of the nondissolved drug excess. Such limited drug solubility effects are expected in the case of drugs with limited water-solubility. However, it has recently been pointed out that even in the case of freely water-soluble drugs and highly swollen polymeric networks, limited drug solubility effects can be of importance for drug release [32]. This should not be underestimated.

In addition, HPMC chains disentangle from the polymeric network as soon as a critical water content is reached [20,33,34]. Disentangled polymer chains subsequently diffuse through the liquid unstirred boundary layer surrounding the tablet into the well stirred bulk fluid. Note that the swelling \& dissolution rates of HPMC depend on the polymer molecular weight, degree of hydroxypropyl- and methyl-substitution as well as on the distribution of these substituents $[35,36,37]$. Depending on the initial drug loading, drug solubility, HPMC swelling and dissolution rates, up to 3 moving boundaries can be observed in controlled release HPMC tablets: (i) a swelling front, separating the inner dry tablet core (with non-swollen HPMC) from 
the swollen tablet zone; (ii) a diffusion front, separating the swollen polymer still containing non-dissolved drug excess from the swollen polymer containing only dissolved drug; and (iii) an erosion front, separating the polymeric matrix tablet from the bulk fluid.

In order to adjust desired drug release kinetics from HPMC-based matrix tablets different types of other excipients can be added [38,39], for example lactose [40]. The presence of the latter can affect the structure of the resulting HPMC network and the conditions for drug release. In addition, the type of preparation technique of an HPMC-based controlled release matrix tablet might impact the inner system structure and, hence, the resulting drug release rates. For example, the compression of a physical blend of HPMC particles and lactose particles is likely to result in a different matrix structure compared to the compression of a co-processed, e.g. spray agglomerated HPMC:lactose blend. In the latter case, the distribution of the polymer and sugar can be expected to be different. Such co-processed excipients might offer interesting advantages from a manufacturing perspective. For instance, the flowability and compactability of the resulting drug:excipient blends might be improved. However, differences in the inner tablet structure might also affect the resulting drug release kinetics, e.g. via altered penetration rates of water into the systems.

The aim of this study was to investigate how a co-processed (spray agglomerated) 50:50 blend of HPMC and lactose performs compared to a simple physical mixture of HPMC and lactose. Different types of propranolol $\mathrm{HCl}$ loaded tablets were prepared by direct compression, varying the drug loading from 0 to $60 \%$. In addition, granules containing the drug, HPMC and lactose were prepared by wet granulation and compressed into tablets, for reasons of comparison (likely exhibiting yet another distribution of the drug and excipients in the tablets). For direct compression, a direct compression HPMC grade (Methocel K4M Premium DC) was used. For wet granulation, a "standard” HPMC grade (Benecel K4M) was used, to reflect the choice that would likely be made in practice. The flowability and compactability of the different 
lubricated powder/granule blends was measured, as well as the key features of the resulting tablets: water uptake rates, changes in tablet dimensions upon exposure to $0.1 \mathrm{M} \mathrm{HCl}$ and phosphate buffer $\mathrm{pH} 7.4$, as well as propranolol release kinetics.

\section{Materials and methods}

\subsection{Materials}

Propranolol $\mathrm{HCl}$ (Fagron, Saint-Denis, France); $\alpha$-lactose monohydrate (spray agglomerate, Tablettose 80) and "a 50:50 co-processed spray agglomerate of hydroxypropyl methylcellulose \& $\alpha$-lactose monohydrate" (RetaLac) (Meggle, Wasserburg, Germany); hydroxypropyl methylcellulose (HPMC, Methocel K4M Premium DC or Benecel K4M; Stobec, St-Jerome, Canada); magnesium stearate (Cooperation pharmaceutique francaise, Melun, France).

\subsection{Tablet preparation}

\subsubsection{Direct compression with RetaLac}

Appropriate amounts of propranolol $\mathrm{HCl}$ and RetaLac were blended in a Turbula mixer (T2C; Bachofen, Basle, Switzerland) at $38 \mathrm{rpm}$ for $5 \mathrm{~min}$. The drug content was varied between 0 and $60 \%$ (Table 1). Magnesium stearate was added and the blend was further mixed in the Turbula mixer at $38 \mathrm{rpm}$ for $5 \mathrm{~min}$. Cylindrical tablets were prepared with an instrumented single-punch tableting machine (Frogerais OA, Paris, France) using flat-faced punches (11.3 $\mathrm{mm}$ in diameter) and the LilTab software (University of Lille, Lille, France). The weight (300 mg) and hardness of the tablets (60-70 N, Tablet Tester 8M; Dr. Schleuniger Pharmatron, Solothurm, Switzerland) were kept constant, unless otherwise stated. The resulting tablet height 
was $2.5 \mathrm{~mm}$. The tablet dimensions were measured using a micrometer gauge (Digimatic Micrometer; Mitutoyo, Tokyo, Japan).

\subsubsection{Direct compression with physical HPMC:lactose blends}

Equal amounts of HPMC (Methocel K4M Premium DC: direct compression grade) and lactose were blended in a Turbula mixer (T2C) at $38 \mathrm{rpm}$ for $5 \mathrm{~min}$. Appropriate amounts of propranolol $\mathrm{HCl}$ were added to prepare tablets with a drug content between 0 and $60 \%$ (Table 2). The mixtures were blended in the Turbula mixer at $38 \mathrm{rpm}$ for $5 \mathrm{~min}$. Upon addition of magnesium stearate, the powder blends were further mixed in the Turbula mixer at $38 \mathrm{rpm}$ for 5 min. Cylindrical tablets were manufactured with a single-punch tableting machine as described in section 2.2.1.

\subsubsection{Wet granulation and compression}

Equal amounts of HPMC (Benecel K4M) and lactose were blended in a planetary mixer (level 3, Robot Titanium KM010 Chef; Kenwood, Clichy, France) for 5 min. Appropriate amounts of propranolol $\mathrm{HCl}$ were added to prepare tablets with a drug content between 0 and $60 \%$ (Table 2). The mixtures were blended in the planetary mixer for 5 min (level 4). A 50:50 ethanol:water (v/v) mixture was dropwise added to the dry powder blends (150 g) under agitation (planetary mixer, level 4) until an appropriate texture for granulation was reached. The resulting wet mass was immediately processed using an oscillating granulator ("MG"; Frewitt, Fribourg, Switzerland), equipped with a $2 \mathrm{~mm}$ mesh size sieve. The obtained granules were dried in an oven at $60{ }^{\circ} \mathrm{C}$ overnight and again passed through a $2 \mathrm{~mm}$ mesh size sieve ("MG"). Prior to compression, the granules were lubricated with magnesium stearate (Table 2) in a Turbula mixer (T2C) at $38 \mathrm{rpm}$ for $5 \mathrm{~min}$. Cylindrical tablets were manufactured with a single-punch tableting machine as described in section 2.2.1. Note that only tablets loaded with 
0 or $10 \%$ drug could be prepared using this wet granulation - compression procedure: At higher propranolol $\mathrm{HCl}$ loadings, it was difficult to pass the dried granules through the $2 \mathrm{~mm}$ mesh size sieve, the weight and hardness of the tablets varied extensively, and the compression forces required to achieve the targeted hardness $(60-70 \mathrm{~N})$ approached the technical limits of the tableting machine. No efforts were made in this study to optimize the granulation conditions: This was beyond the scope of this work, since even if the granules' properties would have been improved, a wet granulation step always causes additional costs and production times compared to direct compression.

\subsection{Characterization of the powders, granules and blends thereof}

The particle size distributions of RetaLac and physical HPMC:lactose blends were determined using a laser diffractometer (300RF lens, Mastersizer S; Malvern, Worcestershire, UK). The particle size distribution of the granules (consisting of drug, HPMC and lactose, prepared by wet granulation) was determined via a sieve analysis ("3D”; Retsch, Haan, Germany).

The morphology of the particles in RetaLac, physical HPMC:lactose 50:50 blends and of the granules (consisting of drug, HPMC and lactose, prepared by wet granulation) was studied by optical microscopy and scanning electron microscopy (SEM). In the first case, an optical image analysis system (“SMZ-U”; Nikon, Tokyo, Japan), equipped with an AxioCam ICc1 camera (Axiovision Software; Carl Zeiss MicroImaging, Jena, Germany), was applied. For SEM, a JEOL Field Emission Scanning Electron Microscope (JSM-7800F, Tokyo, Japan) was used (accelerating voltage: $1 \mathrm{kV}$ ). Samples were fixed with carbon tabs (Agar Scientific, Stansted, UK), and sputter-coated with a thin chrome layer (Gatan 682; Precision Etching and Coating System, Pleasanton, USA).

The flowability of the lubricated powder/granule blends was characterized using a 
funnel as described in the Eur. Pharm. 7.0 (2.9.16.-2). The time required for a $100 \mathrm{~g}$ sample to flow through the funnel was recorded $(\mathrm{n}=3$, mean values $+/$ - standard deviation are reported).

The tapped volumes of the lubricated powder/granule blends were determined using the apparatus described in the Eur. Pharm. 7.0 (2.9.34.-3). One hundred g samples were carefully introduced into the graduated cylinder. The volumes after 10 and 500 taps $\left(\mathrm{V}_{10}\right.$ and $\left.\mathrm{V}_{500}\right)$ were recorded $(\mathrm{n}=3$, mean values $+/$ - standard deviation are reported).

The compactability (ability to form tablets) of the lubricated powder blends /granules was evaluated using an instrumented single-punch press (Frogerais OA; LilTab software), equipped with $11.3 \mathrm{~mm}$ diameter flat-faced punches. The following parameters were recorded: (i) force measured at the upper punch, (ii) force measured at the lower punch, (iii) ejection force, and (iv) residual force.

\subsection{Tablet characterization}

The friability of the tablets was measured using a friability tester (Erweka, Heusenstamm, Germany) according to the USP 41 ( $\mathrm{n}=3$, mean values +/- standard deviation are reported).

The hardness of the tablets $(\mathrm{n}=5)$ was measured immediately after compression using a Tablet Tester 8M (Dr. Schleuniger Pharmatron).

Drug release from the tablets was measured using the USP paddle apparatus (USP 41, $80 \mathrm{rpm}, 37^{\circ} \mathrm{C}$; AT 7 smart, Sotax; Basel, Switzerland) in $900 \mathrm{~mL} 0.1 \mathrm{M} \mathrm{HCl}$ and phosphate buffer $\mathrm{pH} 7.4$ (USP 41). Sinkers were used to prevent the tablets from floating or sticking to the vessel walls. At predetermined time points, $5 \mathrm{~mL}$ samples were withdrawn, filtered $(5 \mu \mathrm{m}$ syringe filter; BD, Le Pont de Claix, France) and analyzed spectrophotometrically for their drug content (UV-1650 PC, $\lambda=291 \mathrm{~nm}$; Shimadzu, Champs-sur-Marne, France). All experiments were conducted in triplicate, mean values +/- standard deviation are reported. 
The water uptake and dry mass loss kinetics of the tablets upon exposure to $0.1 \mathrm{M} \mathrm{HCl}$ or phosphate buffer $\mathrm{pH} 7.4$ (USP 41) were determined gravimetrically. The tablets were treated as for the drug release measurements (described above). They were weighed before exposure to the bulk fluids $(t=0)$. At predetermined time points, samples were withdrawn, excess water carefully removed using Kimtech precision wipes (Kimberly-Clark, Kent, UK), accurately weighed [wet mass $(t)$ ], and dried in an oven ("E28"; Binder, Tuttlingen, Germany) at $45^{\circ} \mathrm{C}$ to constant mass [dry mass ( $t)]$. The water content (\%) and dry tablet mass (\%) at time $t$ were calculated as follows:

$$
\begin{gathered}
\text { water content }(\%)(t)=\frac{\text { wet mass }(t)-\operatorname{dry} \text { mass }(t)}{\operatorname{wet} \operatorname{mass}(t)} * 100 \% \\
\text { dry tablet mass }(\%)(t)=\frac{\operatorname{drymass}(t)}{\operatorname{drymass}(t=0)} * 100 \%
\end{gathered}
$$

where dry mass $(t=0)$ is the dry tablet mass at time $t=0$ (before exposure to the release medium). All experiments were conducted in triplicate, mean values $+/-$ standard deviation are reported.

Dynamic changes in the tablet dimensions (radius and height) upon exposure to $0.1 \mathrm{M}$ $\mathrm{HCl}$ or phosphate buffer $\mathrm{pH} 7.4$ (USP 41) were monitored with a micrometer gauge (Digimatic Micrometer). Tablets were treated as for the drug release measurements (described above). At predetermined time points, samples were withdrawn, excess water carefully removed using Kimtech precision wipes (Kimberly-Clark), and their radius and height were measured in the wet state. All experiments were conducted in triplicate, mean values $+/$ - standard deviation are reported. 


\section{Results and discussion}

The aim of this study was to use HPMC:lactose blends as matrix formers in controlled release tablets (loaded with propranolol $\mathrm{HCl}$ ) and to study the impact of the type of preparation technique on the resulting key properties of the tablets and of the powder/granule blends used for compression. The use of physical HPMC:lactose blends was compared to the use of co-processed HPMC:lactose, prepared by spray agglomeration (available under the tradename RetaLac). Tablets were prepared by direct compression of propranolol $\mathrm{HCl}: \mathrm{HPMC}$ :lactose blends or propranolol $\mathrm{HCl}$ :RetaLac blends, varying the drug content from 0 to $60 \%$. The HPMC:lactose blend ratio was kept constant at 50:50. In addition, tablets were prepared via wet granulation: the drug was wet granulated with 50:50 blends of HPMC and lactose (using 50:50 ethanol:water mixtures). The exact compositions of the investigated tablets are shown in Tables 1 and 2.

\subsection{Flowability and compactability of the powder/granule blends}

Figure 1a shows the flow times of lubricated: (i) propranolol $\mathrm{HCl}$ :RetaLac blends, and (ii) blends of propranolol $\mathrm{HCl}$ with physical HPMC:lactose mixtures. In all cases, $0.5 \%$ magnesium stearate was added as lubricant. A funnel as described in the Eur. Pharm. 7.0 (2.9.16.-2) and $100 \mathrm{~g}$ samples were used. As it can be seen, the flowability of the drug:RetaLac blends was better than the flowability of the physical blends of the drug, HPMC and lactose, irrespective of the drug loading. The flow times of the (lubricated) granules obtained by wet granulation with 0 and $10 \%$ drug loading were in the range of 7 to $8 \mathrm{~s}$ (data not shown), but these values should be viewed with caution, since no efforts were undertaken in this study to optimize the granulation process: This was beyond the scope of this work, since even if the granules' properties would have been improved, a wet granulation step causes additional costs 
and production times compared to direct compression. The aim in this study with respect to wet granulation was to see whether this additional processing step is likely to impact the resulting drug release kinetics from the tablets to a noteworthy extend. Under the selected conditions, it was not possible to prepare tablets via wet granulation with propranolol $\mathrm{HCl}$ loadings of $20 \%$ or more, due to difficulties encountered when passing the dried granules through the $2 \mathrm{~mm}$ mesh size sieve, extensive variability of the weight and hardness of the tablets and very high required compression forces (approaching the technical limits of the tableting machine).

The observed differences in the flowability of the powder/granule blends can probably (at least partially) be attributed to differences in the sizes of the particles/granules [Figure 2, Tables S1 and S2; D (v, 0.9): RetaLac - $177 \mu \mathrm{m}$, physical HPMC:lactose blend (50:50) $189 \mu \mathrm{m}]$ as well as to differences in the shape and surface morphology of the particles/granules (Figure 3). In practice, good flowability is crucial for efficient die filling and high production speeds.

Furthermore, the tapped volumes $\mathrm{V}_{10}$ and $\mathrm{V}_{500}$ were determined for the different lubricated powder/granule blends, using the apparatus described in the Eur. Pharm. 7.0 (2.9.34.3). Figure $1 \mathrm{~b}$ shows the results $\left(\mathrm{V}_{10}-\mathrm{V}_{500}\right)$ obtained for the lubricated: (i) propranolol $\mathrm{HCl}$ :RetaLac blends, and (ii) blends of propranolol $\mathrm{HCl}$ with physical HPMC:lactose mixtures. The values for lubricated granules obtained by wet granulation loaded with 0 and $10 \%$ drug were around 10 to $11 \mathrm{~mL}$ (data not shown; again, please note that these values need to be seen with caution). Thus, the following tendency was observed for the " $\mathrm{V}_{10}-\mathrm{V}_{500}$ " values: physical drug:HPMC:lactose blends > granules > drug:RetaLac blends. These observations can at least partially be attributed to the different sizes, geometries and surface morphologies of the particles/granules (as described above, e.g. Figures 2 and 3). In practice, low "V $10-\mathrm{V}_{500 "}$ "values are desired, to assure a reliable die filling and efficient inter-particle bond formation during the compression step (high " $\mathrm{V}_{10}-\mathrm{V}_{500}$ " values indicate high amounts of air between the particles, 
air hindering inter-particle bond formation).

The compactability (ability to form tablets) of the lubricated powder blends /granules was evaluated using an instrumented single-punch press, recording the: (i) force measured at the upper punch, (ii) force measured at the lower punch, (iii) ejection force, and (iv) residual force. In addition, the hardness of the tablets was determined using a crushing force tester. As it can be seen in Figure 4, satisfying tablet hardnesses were obtained even at low compression forces in the case of RetaLac and the physical HPMC:lactose mixtures. There was no noteworthy difference between these formulations. In contrast, tablets prepared with granules obtained by wet granulation showed much lower hardness values (data not shown). This indicates limited cohesion between the granules. Also, granule fragmentation during compression likely created fine particles, which further decrease the cohesion of tablets and, thus, their hardness. Again, please note that granule optimization was beyond the scope of this study. In all cases, the addition of $10 \%$ propranolol $\mathrm{HCl}$ did not substantially affect the "hardness vs. compression force" profiles (e.g., Figures 4b vs. 4a).

Figure 5 shows the variations of the (maximum) forces at the upper and lower punches as well as the (maximum) residual and ejection forces measured during the compression of the lubricated drug:RetaLac blends and drug:HPMC:lactose physical mixtures. The propranolol $\mathrm{HCl}$ content was 0 or $10 \%$ (left and right column), respectively. As it can be seen, the compression forces measured at the upper and lower punches were stable in the case of drug:RetaLac blends, which is consistent with the observed good flowability of the respective powders (Figure 1). The die is rapidly filled in a uniform manner. The addition of $10 \%$ propranolol $\mathrm{HCl}$ did not affect the stability of the compression forces, but slightly decreased the force measured at the lower punch, indicating a decrease in the force transmission. The (maximum) residual and ejection forces were close to zero in the case of drug free tablets, thus, friction with and sticking to the die were not noteworthy. The addition of $10 \%$ propranolol $\mathrm{HCl}$ 
led to slightly higher values, which can likely be attributed to the drug properties (but this slight increase can probably be compensated by higher lubricant amounts). Interestingly, the compression forces were less stable and less regular in the case of physical HPMC:lactose mixtures (Figure $5 \mathrm{~b}$ ). This is again consistent with the observed flow times and the $\mathrm{V}_{10}-\mathrm{V}_{500}$ values (which were higher than in the case of drug:RetaLac blends, Figure 1). The presence of more air between the particles in physical HPMC:lactose mixtures can be expected to lead to higher variations in the die filling and, thus, in the compression forces. In particular, the addition of $10 \%$ propranolol $\mathrm{HCl}$ lead to variable compression forces in the case of physical HPMC:lactose mixtures. In the case of the granules obtained by wet granulation, the variations in the forces measured at the upper and lower punches were considerable (data not shown). Again, please note that the granules were not optimized in this study.

\subsection{Friability, water uptake and drug release of/from the tablets}

In addition to differences in the flowability and compatibility of drug:HPMC:lactose blends, the type of preparation technique of these mixtures can be expected to affect the distribution of the compounds within the resulting tablets. These differences might eventually lead to different key properties of the tablets, such as friability, water uptake/swelling and drug release. Figure 6 shows the friability of the tablets prepared by direct compression of drug:RetaLac blends, direct compression of drug:HPMC:lactose physical mixtures and of tablets prepared via wet granulation, as a function of the drug content. As it can be seen, the RetaLac based tablets showed the lowest friability values, which might be attributed to the particular inner structure of these tablets, resulting from the spray agglomeration of HPMC and lactose.

In contrast, the resulting water uptake kinetics of tablets containing $10 \%$ propranolol $\mathrm{HCl}$, prepared by direct compression of drug:RetaLac blends, drug:HPMC:lactose physical 
mixtures or via wet granulation were very similar, as shown in Figure 7. This indicates that the given differences in the inner tablet structures (distribution of the drug, HPMC and lactose) do not play a noteworthy role for the rate at which water enters the systems upon exposure to $0.1 \mathrm{M}$ $\mathrm{HCl}$. This is important for the conditions for drug release, since the water content of the formed hydrogels might affect the resulting drug dissolution and diffusion [28,41]. Figures 8 and 9 show the dynamic changes in the tablets' diameter and height upon exposure to $0.1 \mathrm{M} \mathrm{HCl}$ and phosphate buffer $\mathrm{pH} 7.4$, respectively. The propranolol $\mathrm{HCl}$ content was 0 or $10 \%$ (left and right columns). As it can be seen, the changes in tablet diameter (Figure 8) were not affected by the type of preparation technique, which is consistent with the water uptake kinetics (Figure 7). However, the tablets prepared via wet granulation generally exhibited a less pronounced expansion in axial direction (changes in the tablets' height illustrated in Figure 9) compared to the tablets prepared by direct compression of drug:RetaLac and drug:HPMC:lactose physical mixtures. This might eventually be attributable to the mechanical stability and the densification of the granules by the wet granulation step, offering resistance to substantial swelling (note that swelling in radial direction was much less pronounced, Figure 8) and/or more rapid gel erosion. The fact that in all cases tablet swelling was more pronounced in axial direction than in radial direction might at least partially be explained by the higher surface area of the tablets in axial direction.

The resulting drug release kinetics from tablets containing $10 \%$ propranolol $\mathrm{HCl}$, prepared by direct compression (of drug:RetaLac blends or drug:HPMC:lactose physical mixtures) or via wet granulation, in $0.1 \mathrm{M} \mathrm{HCl}$ and phosphate buffer $\mathrm{pH} 7.4$ are illustrated in Figure 10. Clearly, the type of preparation technique (and resulting differences in the inner tablet structures) did not affect the drug release kinetics in a substantial manner. This is consistent with the observed very similar changes in the water contents of the systems (Figure 7) and very similar changes in the tablets' diameter. The fact that tablets prepared via 
wet granulation showed less pronounced expansion in axial direction does not seem to be of major importance for the resulting drug release rates.

Furthermore, Figure 11 shows that the resulting drug release rates can effectively be altered by variations in the initial drug content: As it can be seen, the propranolol release rate increased with increasing drug content in all cases, due to the increasing porosity of the systems upon drug release (drug particles are "replaced by water") and the high water-solubility of this drug. Again, no substantial differences were observed with respect to the type of preparation technique (direct compression of drug:RetaLac blends or drug:HPMC:lactose physical mixtures or wet granulation \& compression), irrespective of the drug loading.

\section{Conclusion}

HPMC:lactose blends offer an interesting potential as matrix formers in controlled drug delivery systems. The type of preparation technique can strongly affect the key properties of the powder/granule blends, which are to be compressed (in particular their flowability and compactability). In contrast, the resulting water uptake and drug release kinetics are similar. This indicates that differences in the distribution of the drug, HPMC and lactose, resulting from the different manufacturing procedures, do not affect the conditions for drug release to a substantial extent. From a practical point of view, the use of spray agglomerated "HPMC:lactose" offers the advantage of improved flowability compared to physical HPMC:lactose mixtures.

\section{Acknowledgements}

The authors would like to thank Jeremy Verin from the INSERM U1008 and Mr. 
Alexandre Fadel from the "Centre Commun de Microscopie" (CCM) of the University of Lille ("Plateau technique de le Fédération Chevreul CNRS FR 2638") for their valuable technical help with the SEM pictures.

\section{Conflicts of interest}

One of the authors is employee of Meggle, the company commercializing RetaLac and Tablettose 80. The Editor-in-Chief of the journal is one of the co-authors of this article. The manuscript has been subject to all of the journal's usual procedures, including peer review, which has been handled independently of the Editor-in-Chief. 
Table 1. Composition of the tablets prepared by direct compression with RetaLac.

\begin{tabular}{ccccccccc}
\hline Compound & \multicolumn{7}{c}{ Content, \% } \\
Propranolol HCl & 0.0 & 10.0 & 20.0 & 30.0 & 40.0 & 50.0 & 60.0 \\
RetaLac (50:50 & 99.5 & 89.5 & 79.5 & 69.5 & 59.5 & 49.5 & 39.5 \\
HPMC:lactose) & & & & & & & & \\
& & & & & & & & \\
Magnesium stearate & 0.5 & 0.5 & 0.5 & 0.5 & 0.5 & 0.5 & 0.5 \\
\hline
\end{tabular}

Table 2. Composition of the tablets prepared by direct compression with physical HPMC:lactose mixtures (using Methocel K4M premium DC: direct compression grade) or via wet granulation (using Benecel K4M).

Compound $\quad$ Content, $\%$

\begin{tabular}{|c|c|c|c|c|c|c|c|}
\hline Propranolol & 0.0 & 10.0 & 20.0 & 30.0 & 40.0 & 50.0 & 60.0 \\
\hline \multicolumn{8}{|l|}{$\mathrm{HCl}$} \\
\hline$H P M C$ & 49.75 & 44.75 & 39.75 & 34.75 & 29.75 & 24.75 & 19.75 \\
\hline Lactose & 49.75 & 44.75 & 39.75 & 34.75 & 29.75 & 24.75 & 19.75 \\
\hline Magnesium & 0.5 & 0.5 & 0.5 & 0.5 & 0.5 & 0.5 & 0.5 \\
\hline stearate & & & & & & & \\
\hline
\end{tabular}




\section{Figure captions:}

Fig. 1: Physical mixtures versus co-processed HPMC:lactose blends: a) flowability and b) " $\mathrm{V}_{10}$ - V500" values (differences in tapped volumes) of propranolol HCl:HPMC:lactose:magnesium stearate blends. Please note that some of the standard deviations are too small to be visible.

Fig. 2: Particle size distribution of granules consisting of propranolol $\mathrm{HCl}: \mathrm{HPMC}$ :lactose $(10 \%$ drug loading), prepared by wet granulation.

Fig. 3: Optical microscopy (left column) and scanning electron microscopy (middle and right columns) pictures of surfaces of: RetaLac particles (top row), particles of a physical HPMC:lactose blend (50:50) (middle row), and granules consisting of propranolol HCl:HPMC:lactose (10\% drug loading), prepared by wet granulation (bottom row).

Fig. 4: Physical mixtures versus co-processed HPMC:lactose blends: Tablet hardness as a function of the compression force (upper punch). The tablets contained: a) $0 \%$ propranolol $\mathrm{HCl}$, or b) $10 \%$ propranolol $\mathrm{HCl}$.

Fig. 5: Maximum compression forces measured at the upper \& lower punches and maximum residual \& ejection forces observed during the manufacturing of tablets prepared by direct compression with: a) RetaLac, (b) physical HPMC:lactose blends. The drug loading was 0 or $10 \%$ (as indicated).

Fig. 6: Effects of the type of preparation technique (direct compression with RetaLac, direct compression with physical HPMC:lactose blends and wet granulation \& compression) on the 
tablets' friability. The drug loading was varied from 0 to $60 \%$. The asterisk indicates that the tablets with drug loadings of $20 \%$ or more could not be prepared via wet granulation. Please note that some of the standard deviations are too small to be visible.

Fig. 7: Effects of the type of preparation technique (direct compression with RetaLac, direct compression with physical HPMC:lactose blends and wet granulation \& compression) on the water uptake of the tablets upon exposure to $0.1 \mathrm{M} \mathrm{HCl}$. The propranolol $\mathrm{HCl}$ loading was $10 \%$.

Fig. 8: Effects of the type of preparation technique (direct compression with RetaLac, direct compression with physical HPMC:lactose blends and wet granulation \& compression) on the dynamic changes in the tablets' diameter upon exposure to $0.1 \mathrm{M} \mathrm{HCl}$ or phosphate buffer pH 7.4. The propranolol $\mathrm{HCl}$ loading was 0 or $10 \%$ (initial tablet height: $2.5 \mathrm{~mm}$ and diameter: $11.3 \mathrm{~mm})$.

Fig. 9: Effects of the type of preparation technique (direct compression with RetaLac, direct compression with physical HPMC:lactose blends and wet granulation \& compression) on the dynamic changes in the tablets' height upon exposure to $0.1 \mathrm{M} \mathrm{HCl}$ or phosphate buffer $\mathrm{pH}$ 7.4. The propranolol $\mathrm{HCl}$ loading was 0 or $10 \%$ (initial tablet height: $2.5 \mathrm{~mm}$ and diameter: $11.3 \mathrm{~mm})$

Fig. 10: Effects of the type of preparation technique of the tablets (direct compression with RetaLac, direct compression with physical HPMC:lactose blends and wet granulation \& compression) on the resulting drug kinetics in $0.1 \mathrm{M} \mathrm{HCl}$ or phosphate buffer $\mathrm{pH}$ 7.4. The tablets contained $10 \%$ propranolol $\mathrm{HCl}$. 
Fig. 11: Effects of the drug loading of the tablets (indicated in the diagrams) on propranolol $\mathrm{HCl}$ release in $0.1 \mathrm{M} \mathrm{HCl}$ or phosphate buffer $\mathrm{pH} 7.4$ (left and right column). The systems were prepared by direct compression with RetaLac, direct compression with physical HPMC:lactose blends or wet granulation \& compression. Note that tablets with drug loadings of $20 \%$ or more could not be prepared via wet granulation. 
a)

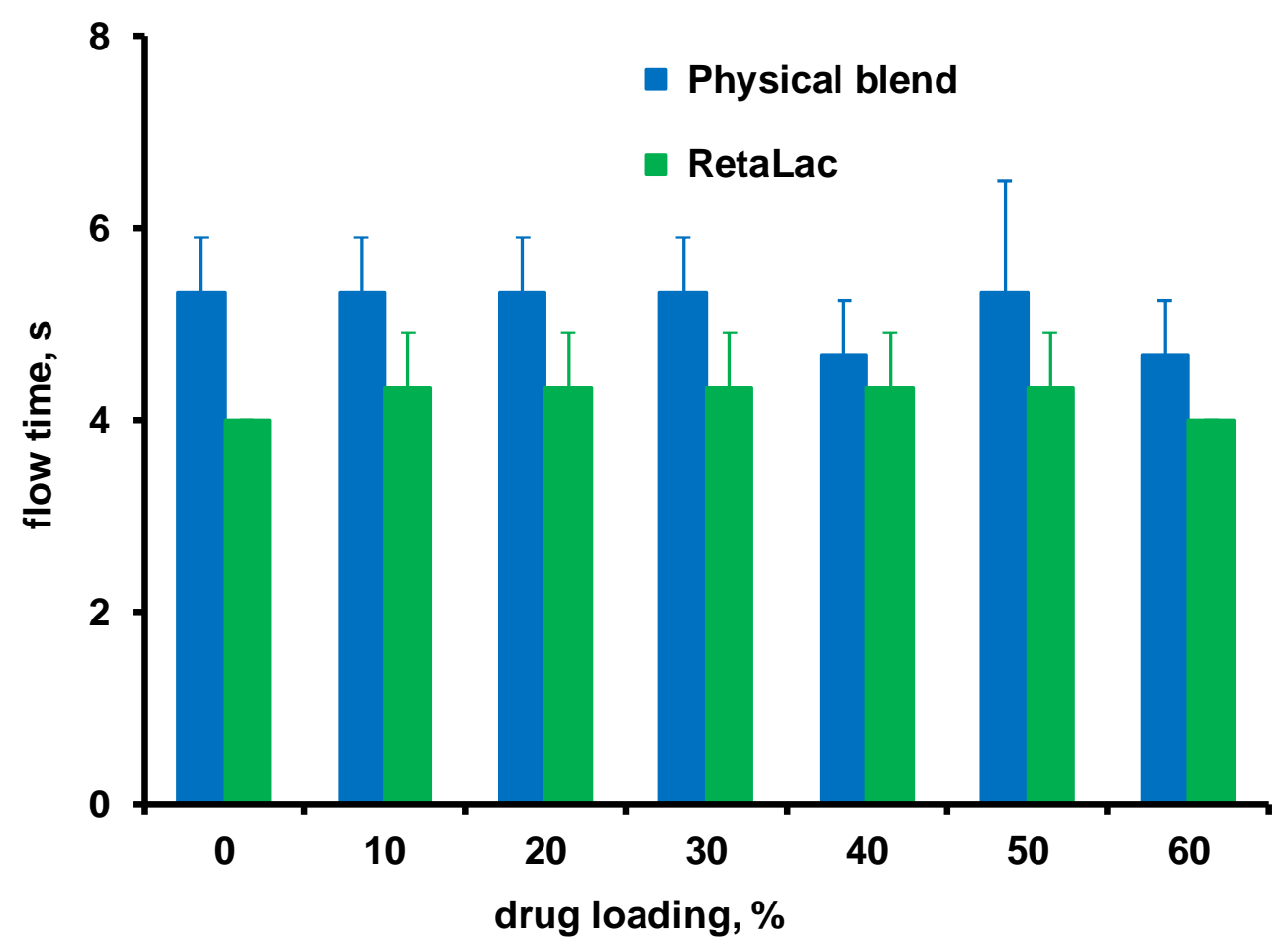

b)

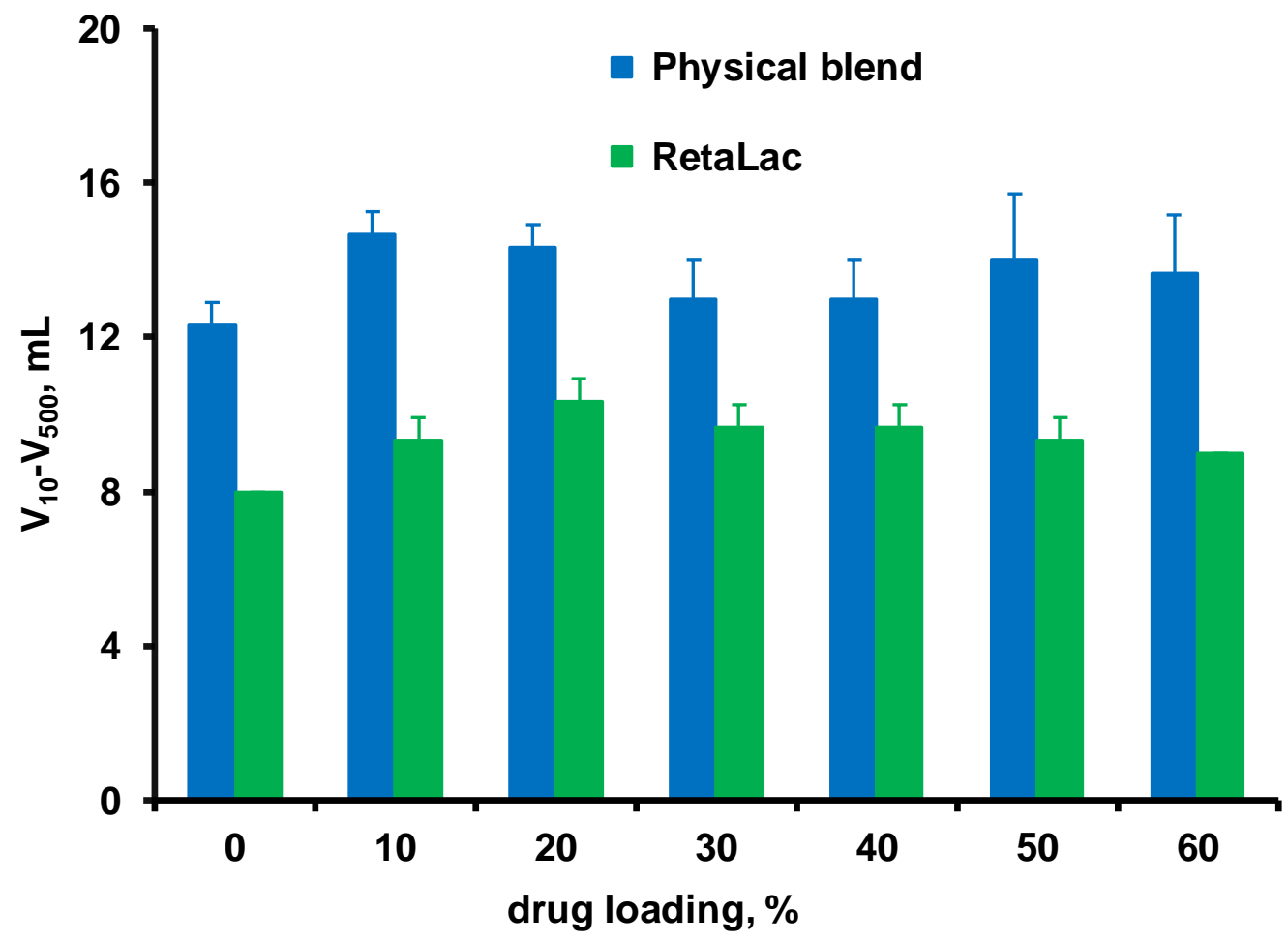

Figure 1 


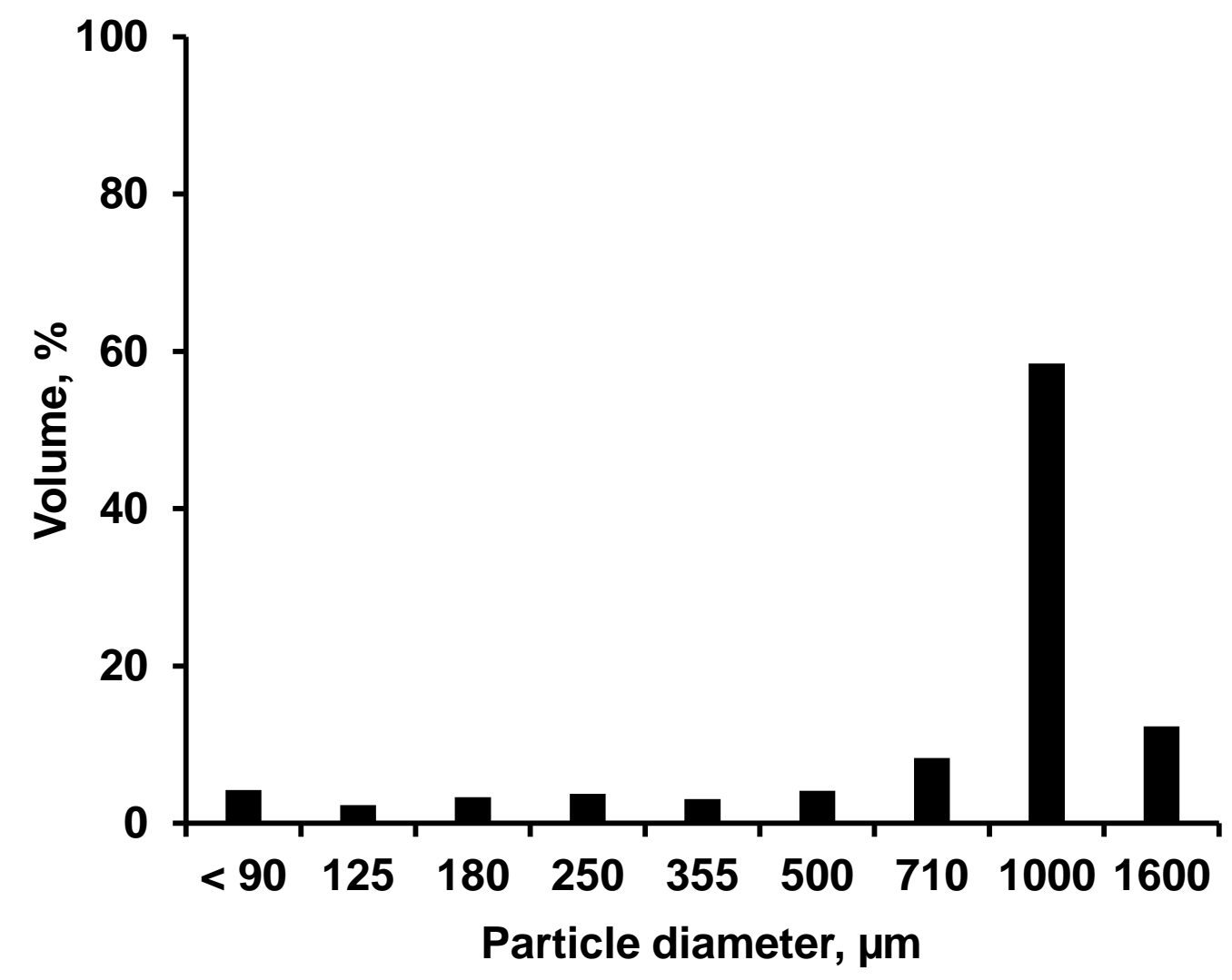

Figure 2 
Optical microscopy

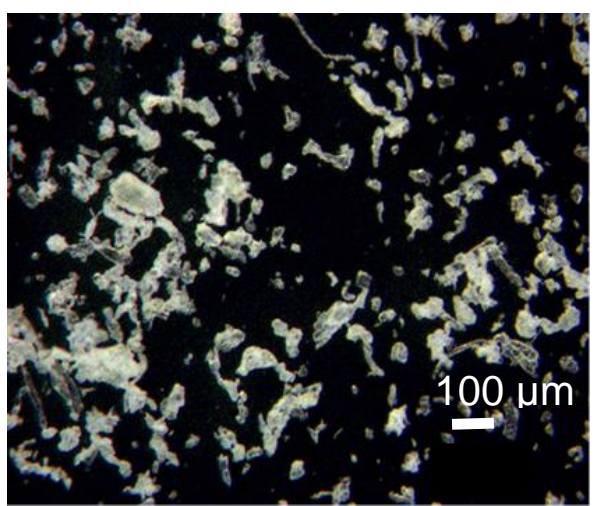

Physical

blend

Wet

granulation
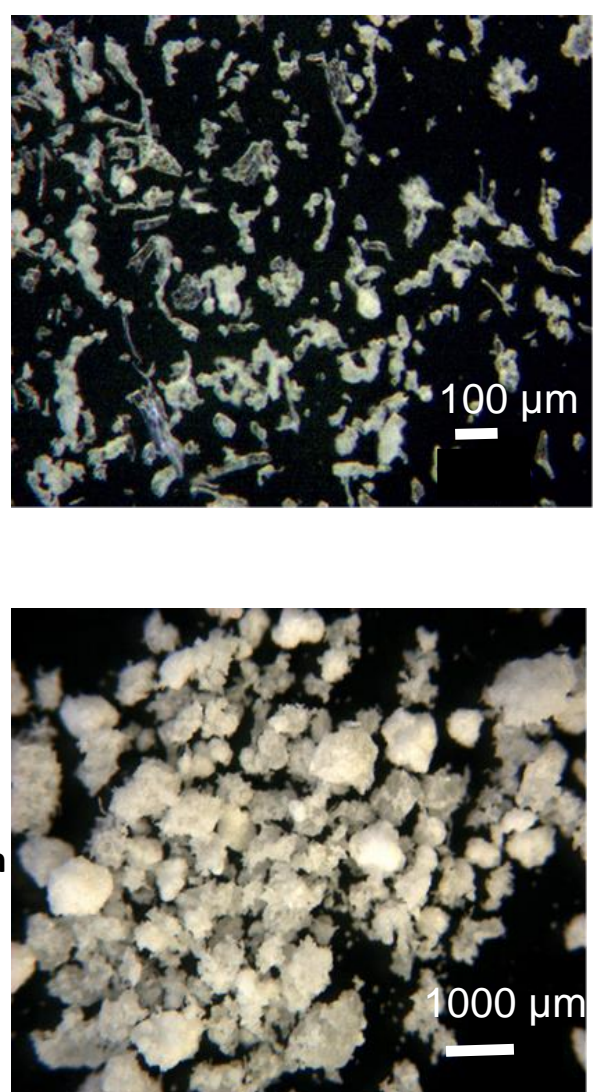

SEM (lower magnification)
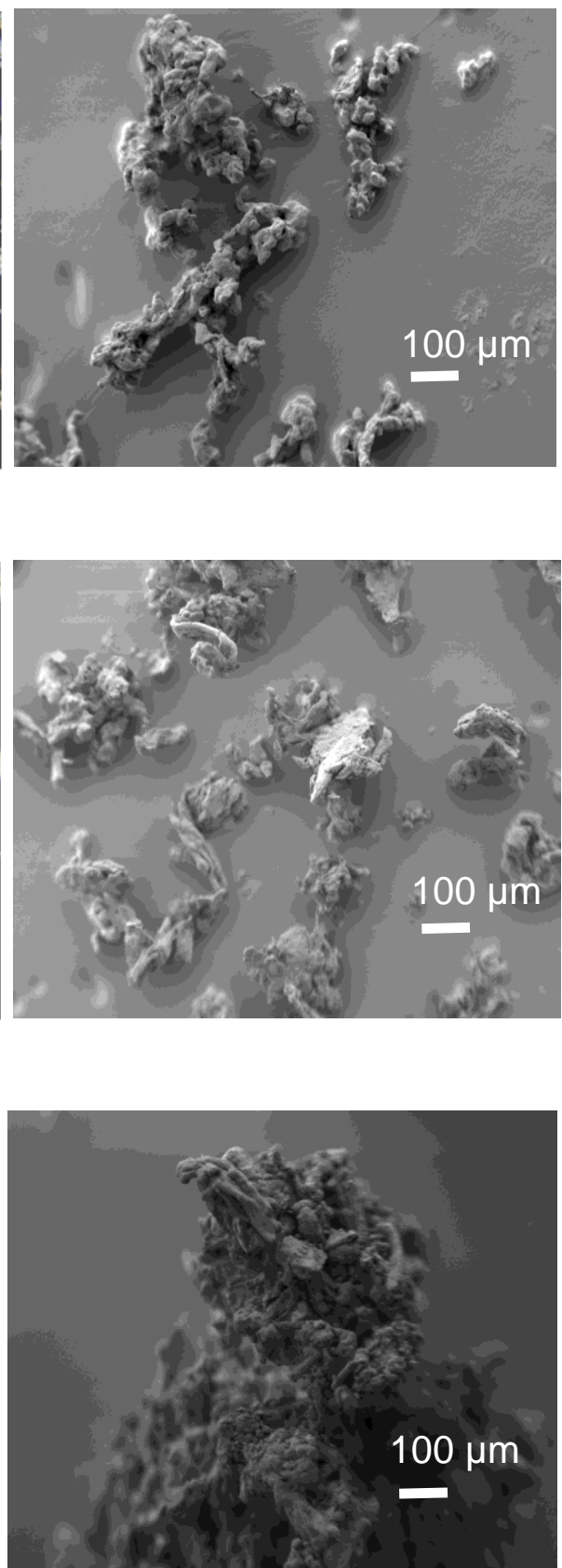

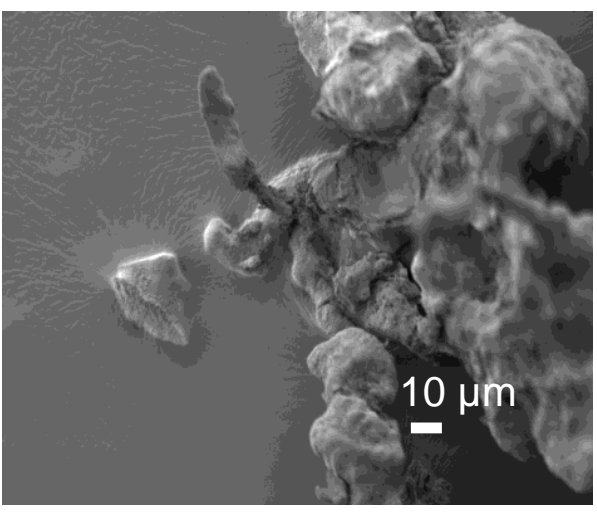

SEM (higher magnification)
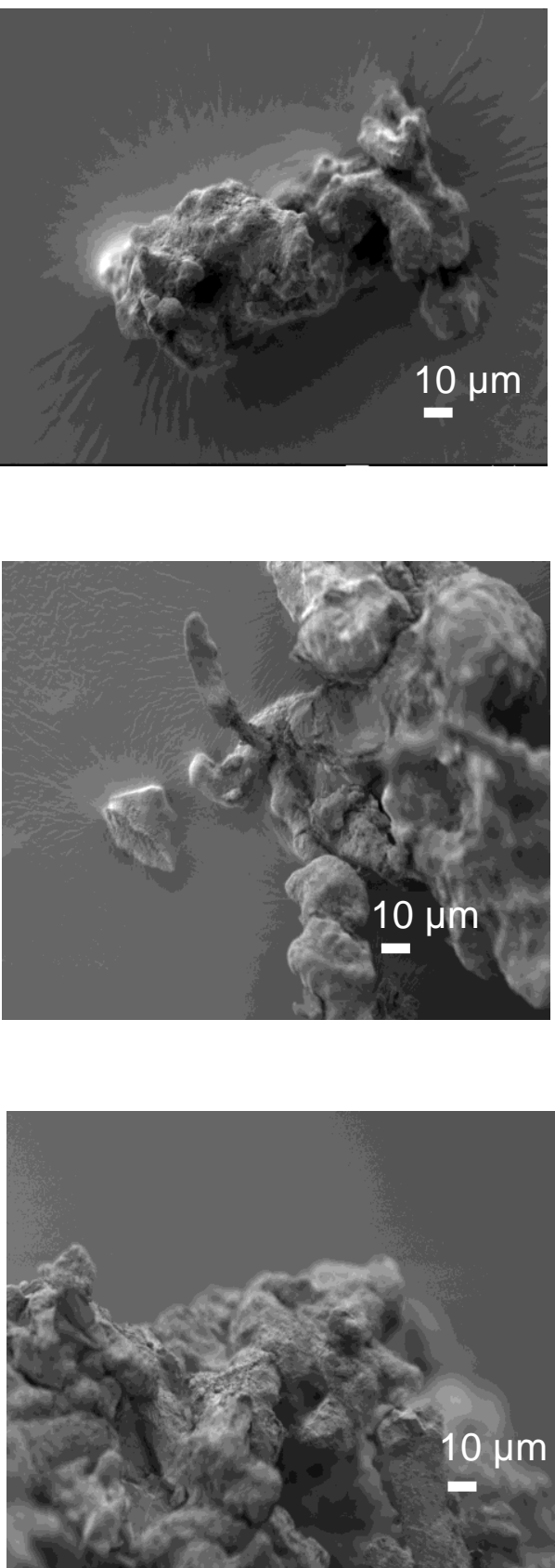

Figure 3 
a)

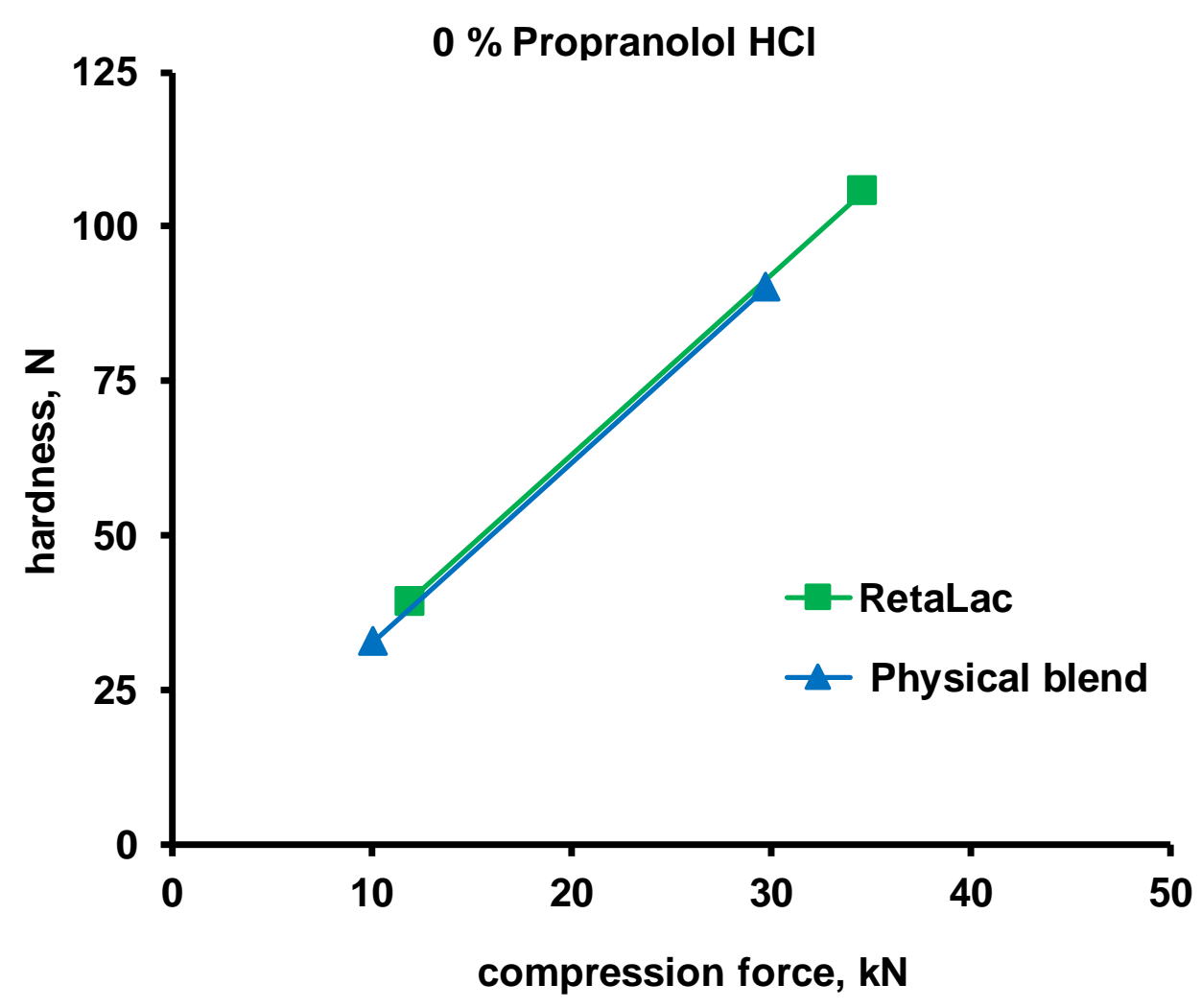

b)

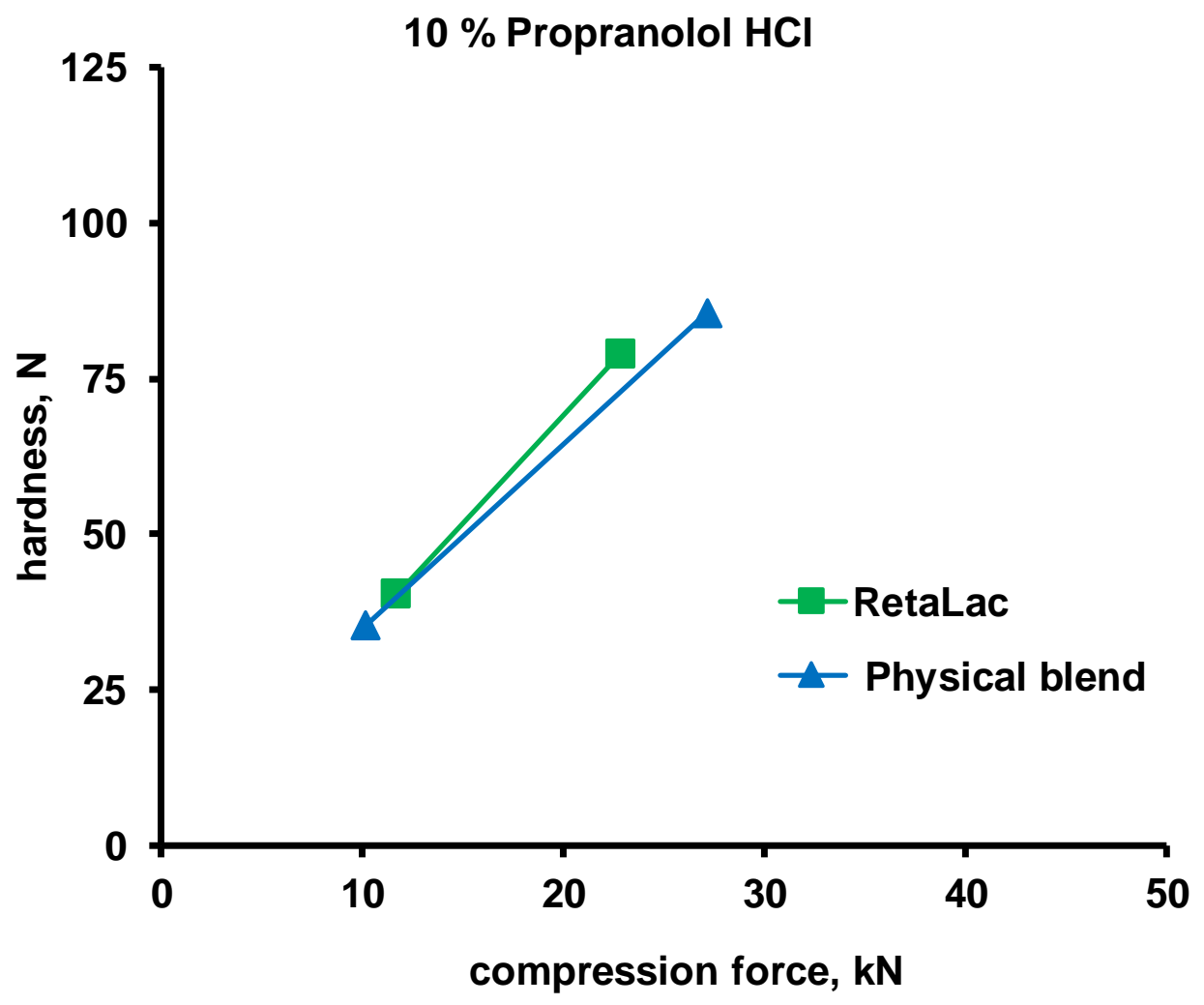

Figure 4 
a)

\section{0 \% Propranolol HCl}

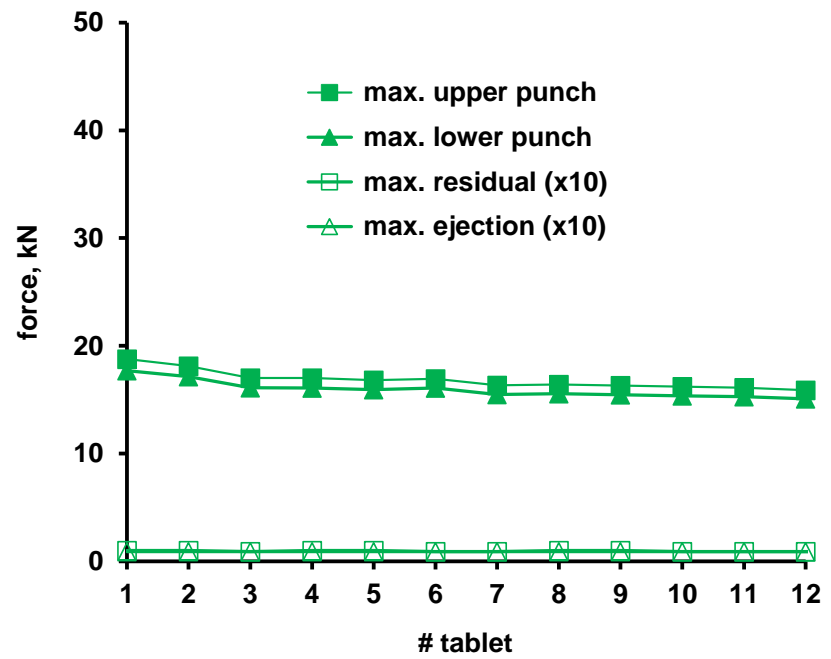

b)

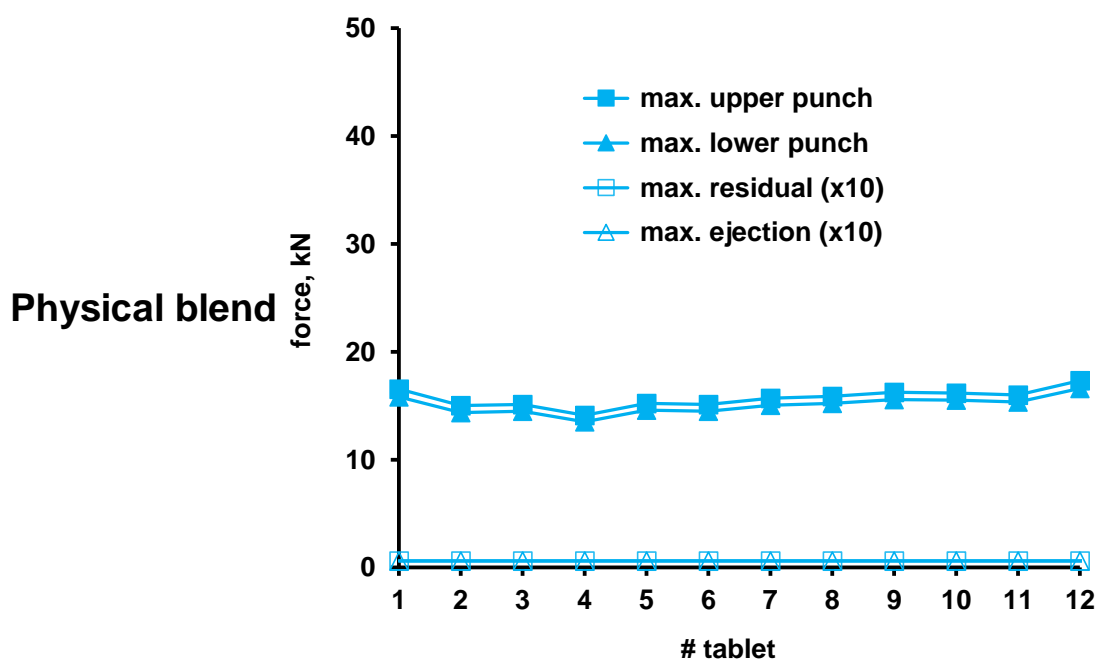

$10 \%$ Propranolol HCl
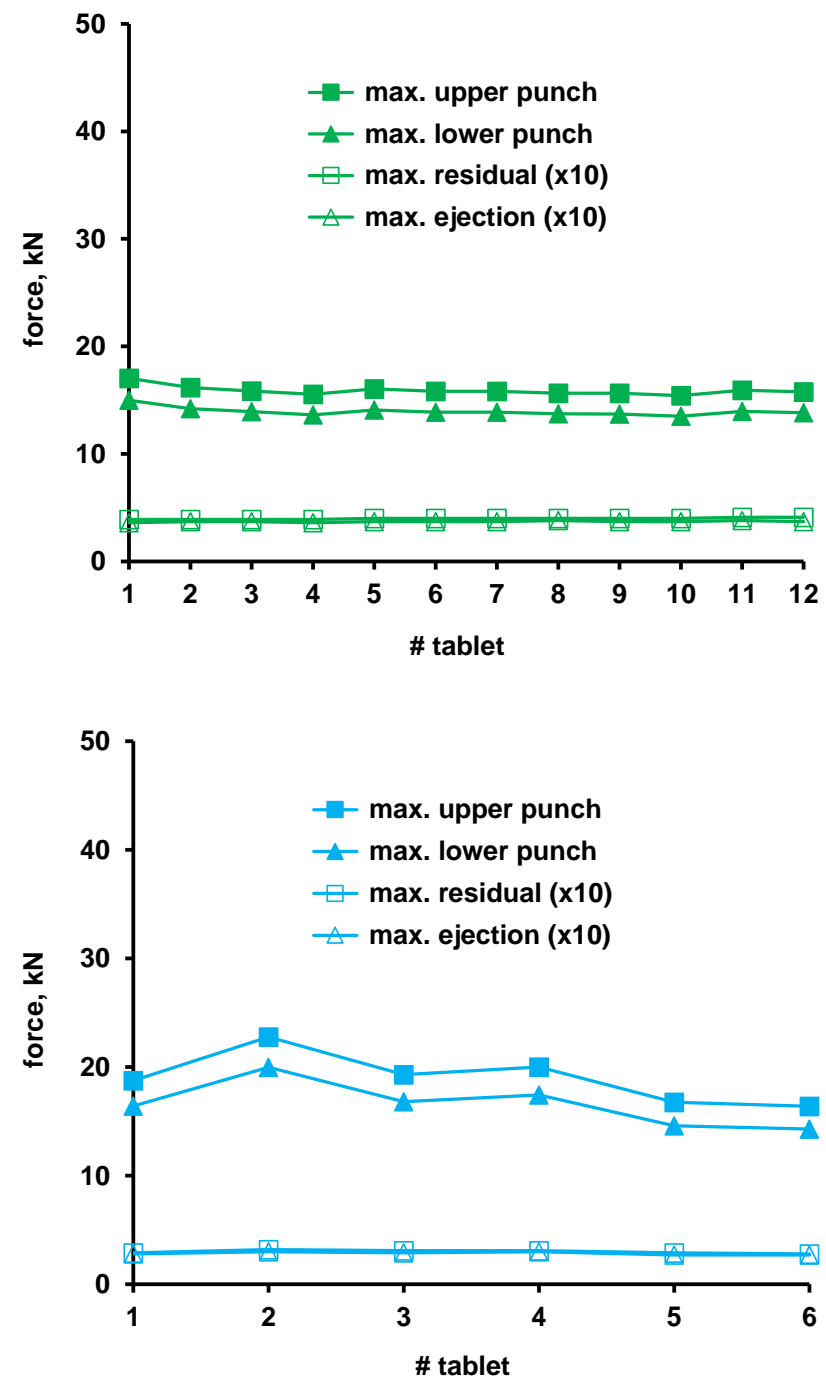

Figure 5 


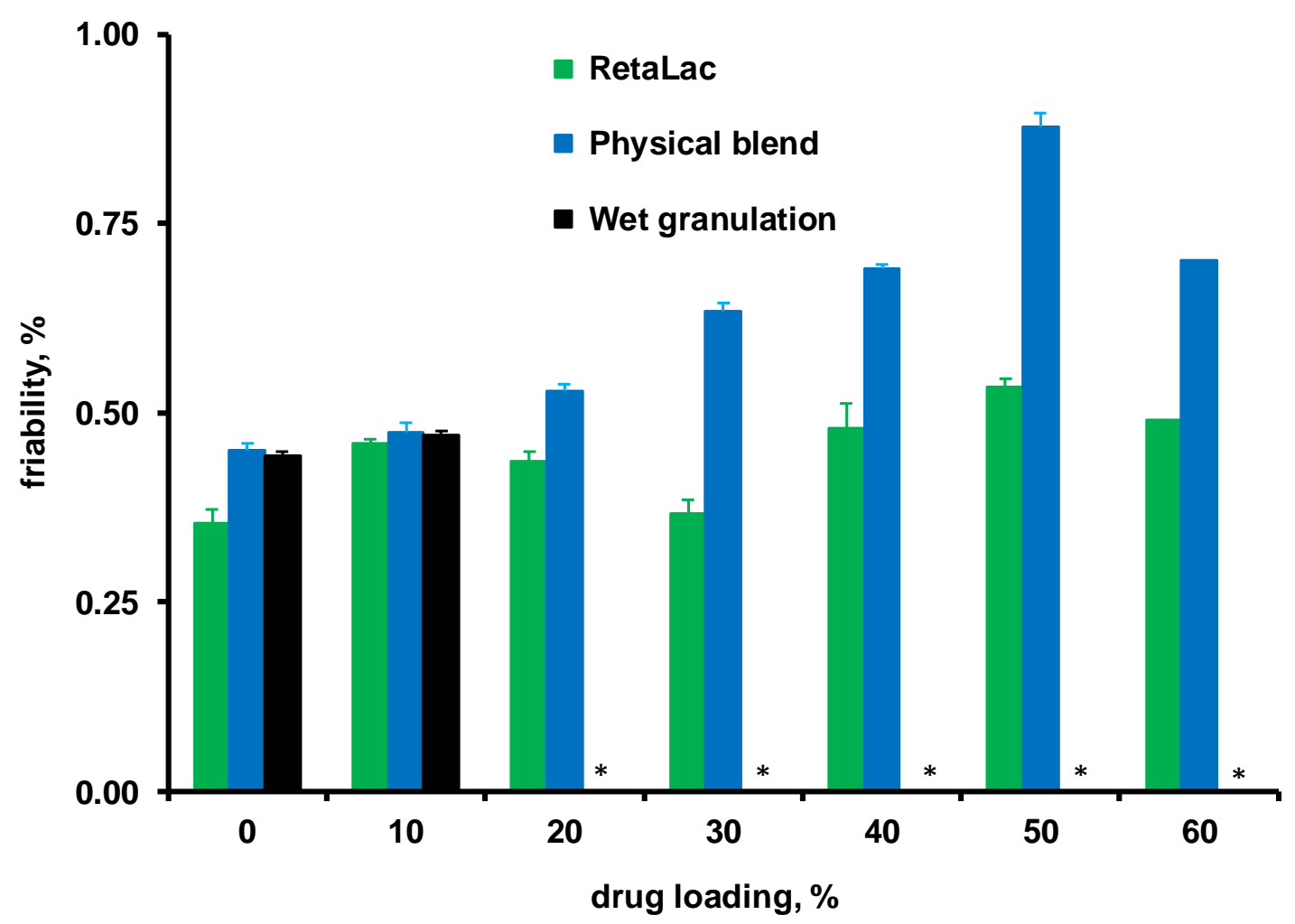

Figure 6 


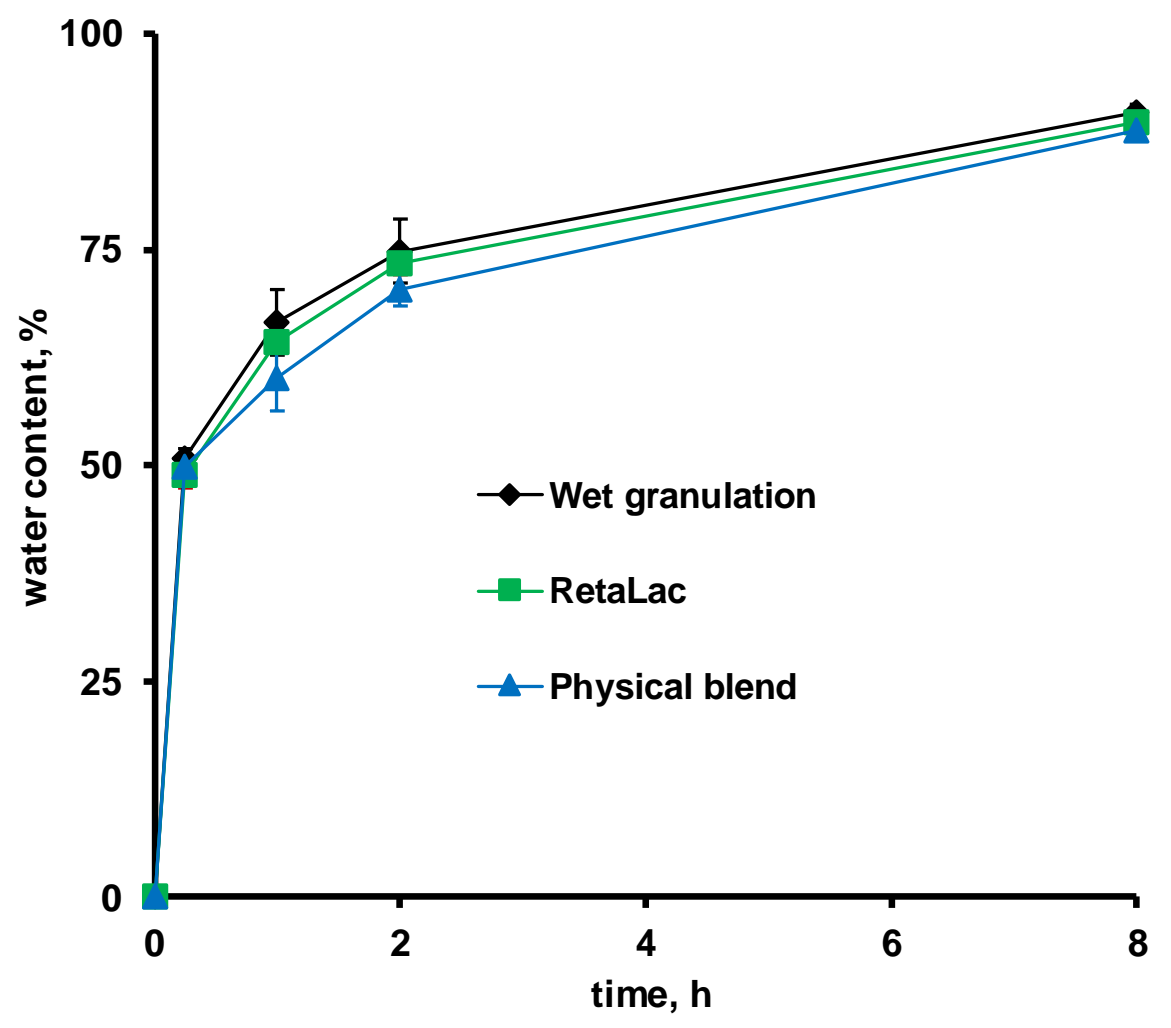

Figure 7 
$0.1 \mathrm{M} \mathrm{HCl}$

pH 7.4
0 \% Propranolol HCl
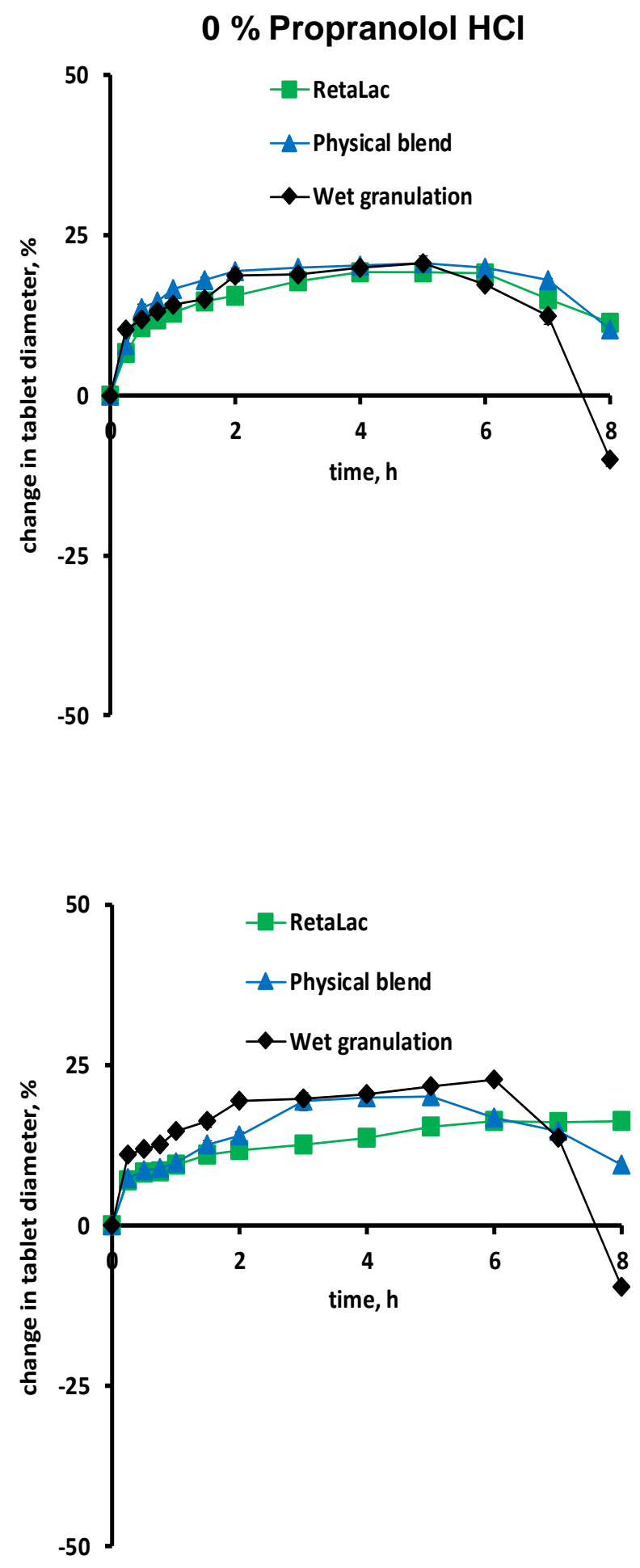

$10 \%$ Propranolol $\mathrm{HCl}$
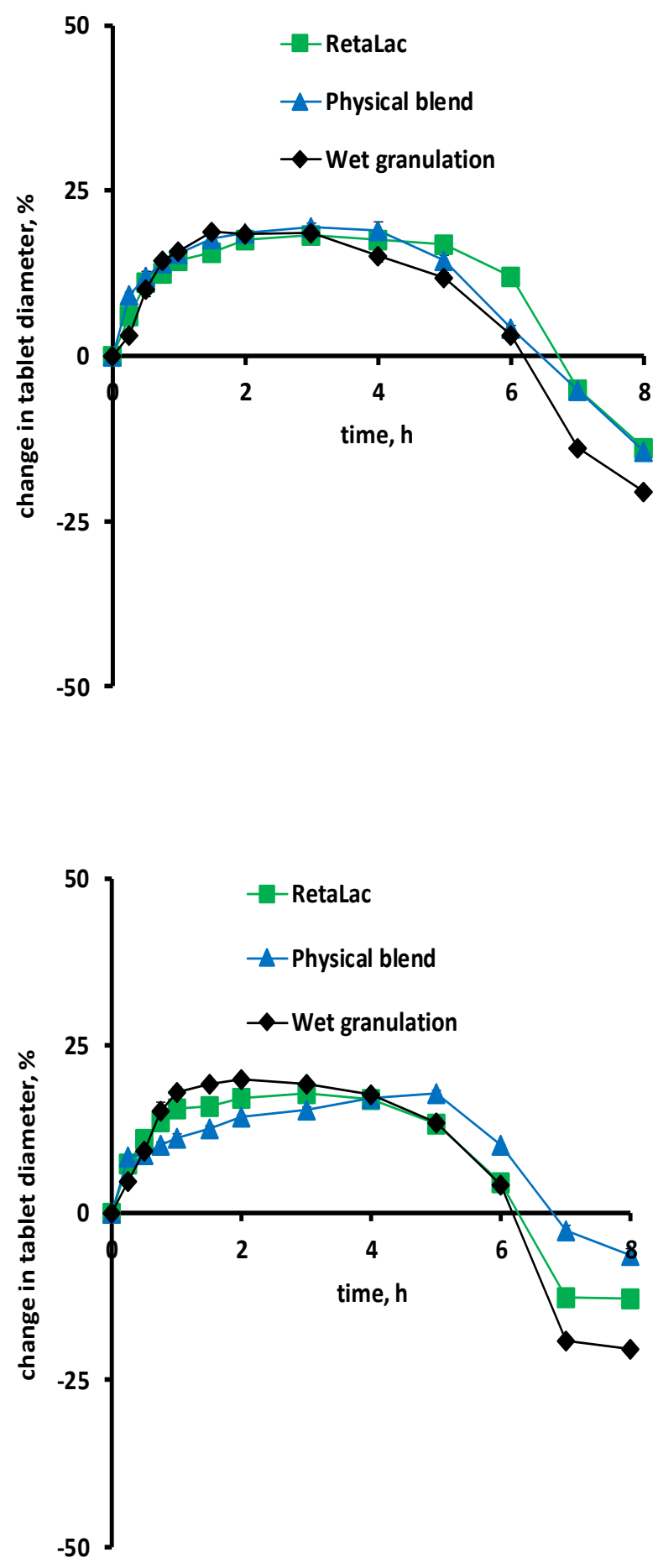

Figure 8 
O \% Propranolol HCl
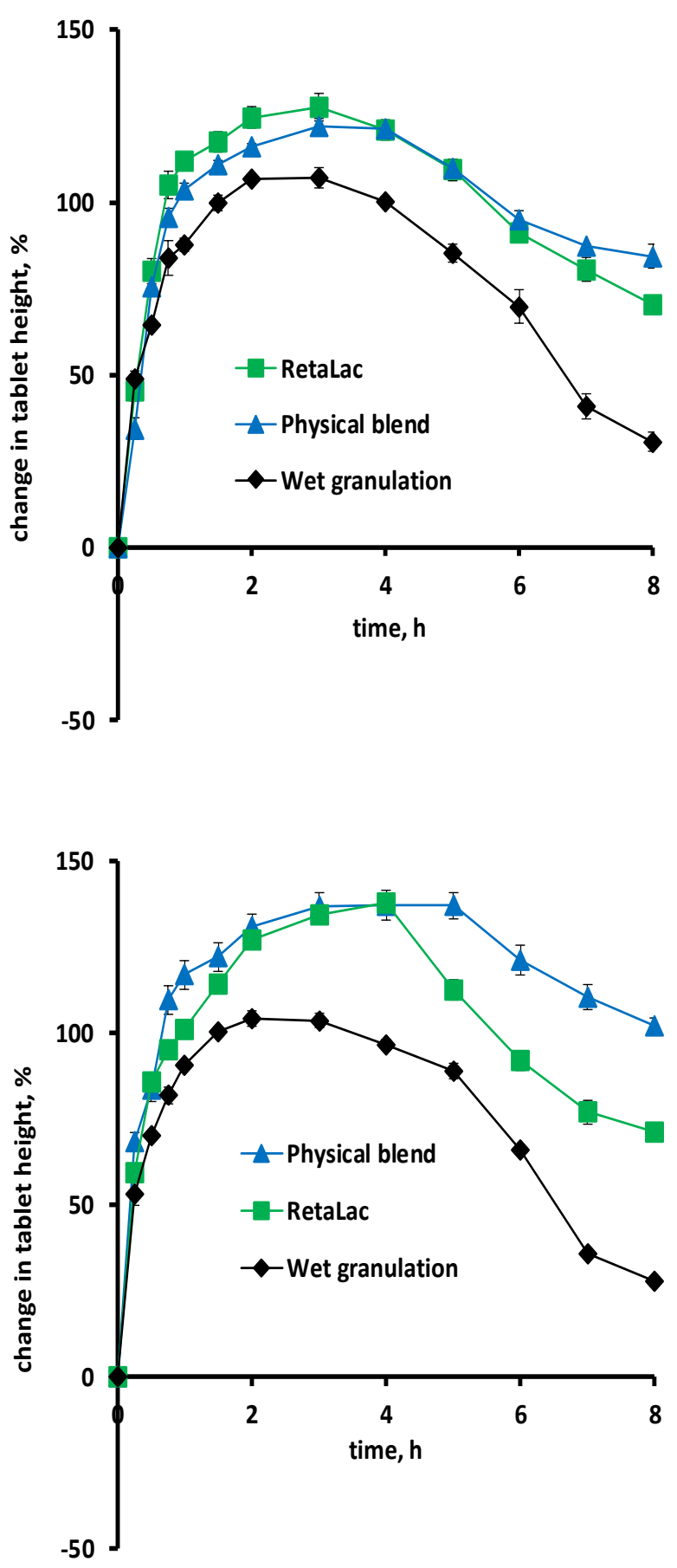

10 \% Propranolol HCl
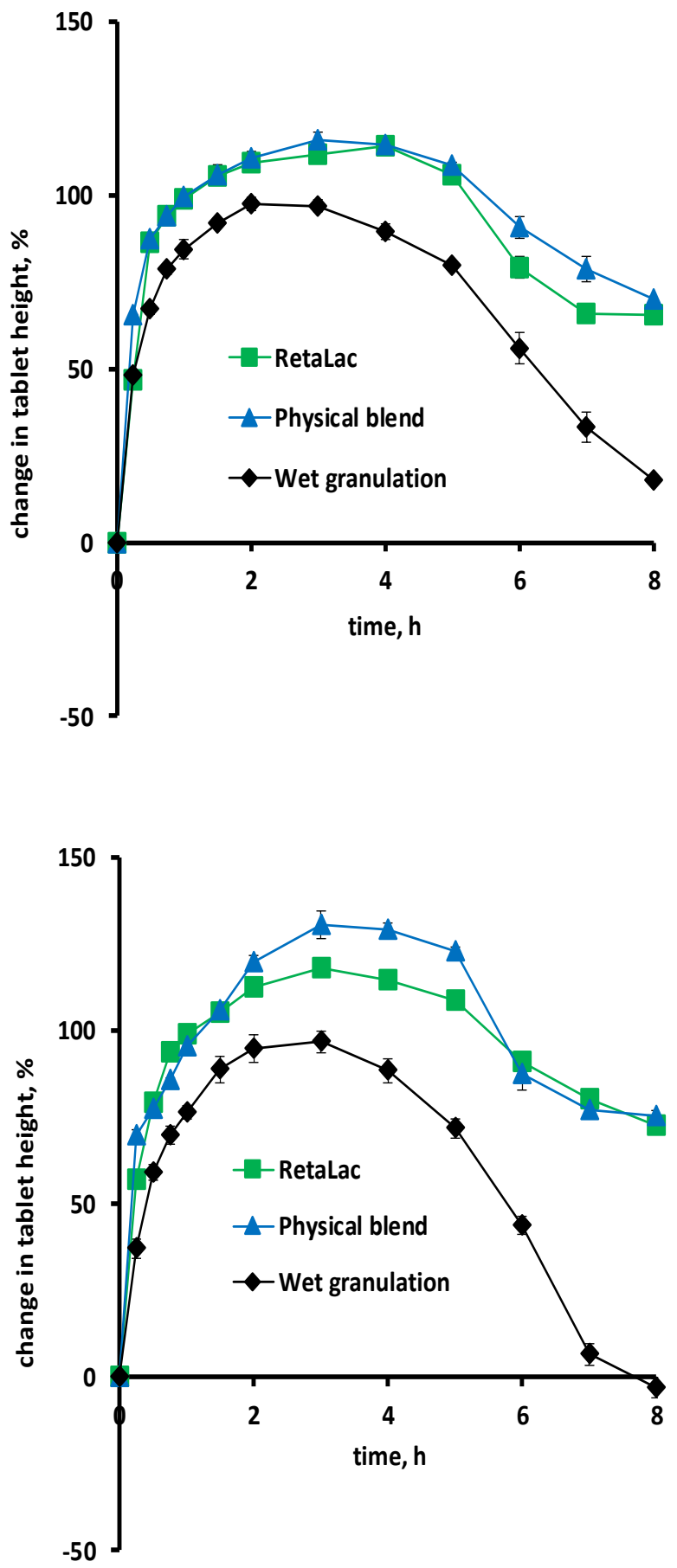

Figure 9 

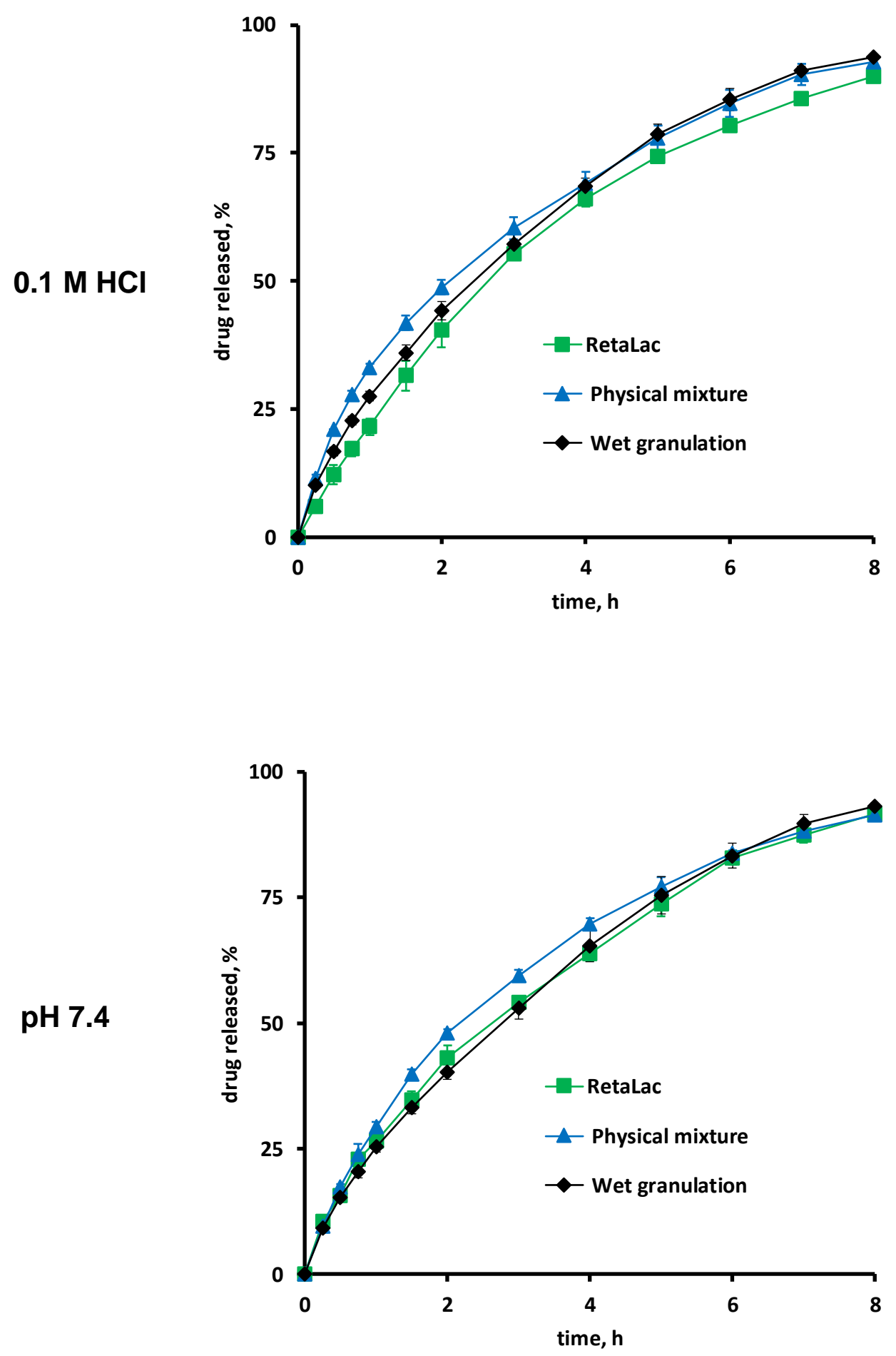

Figure 10 
$0.1 \mathrm{M} \mathrm{HCl}$
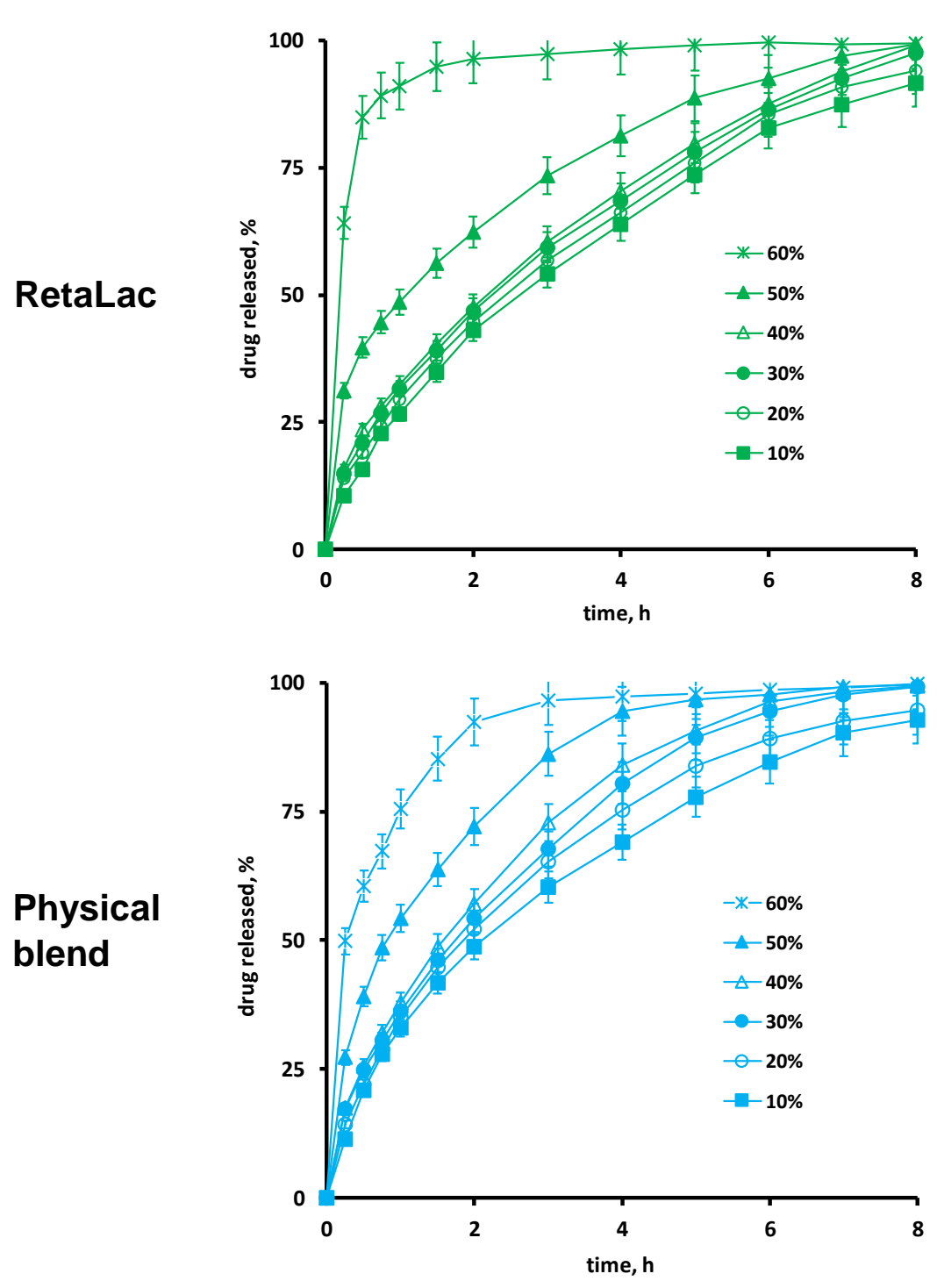

Physical blend

\section{RetaLac}

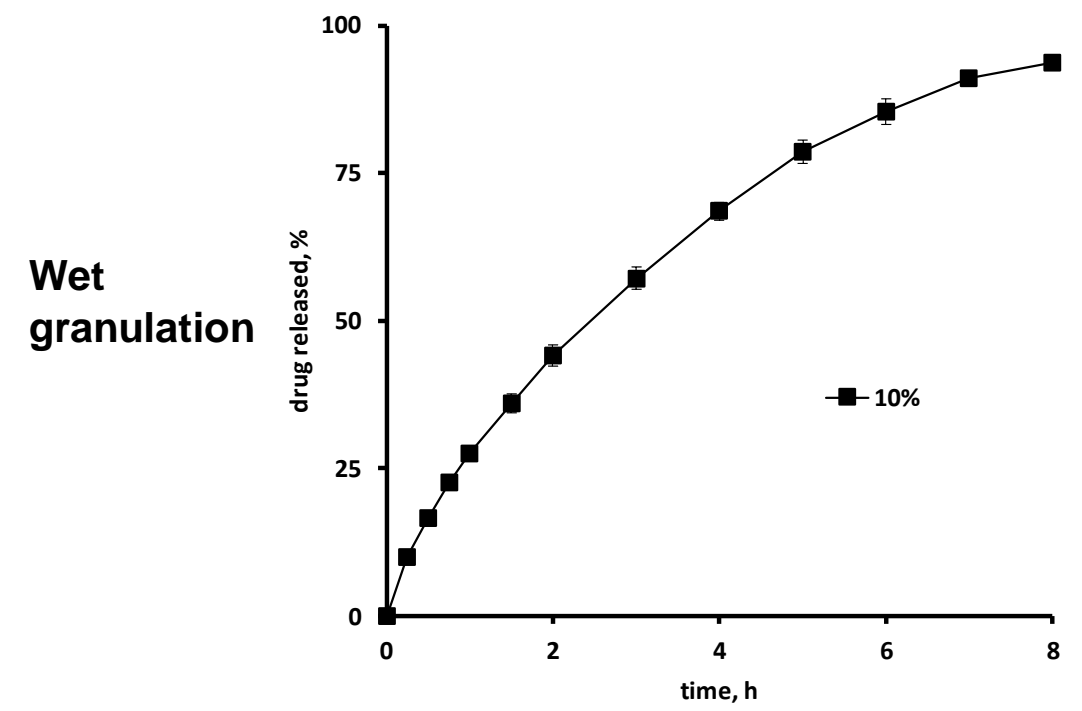

pH 7.4
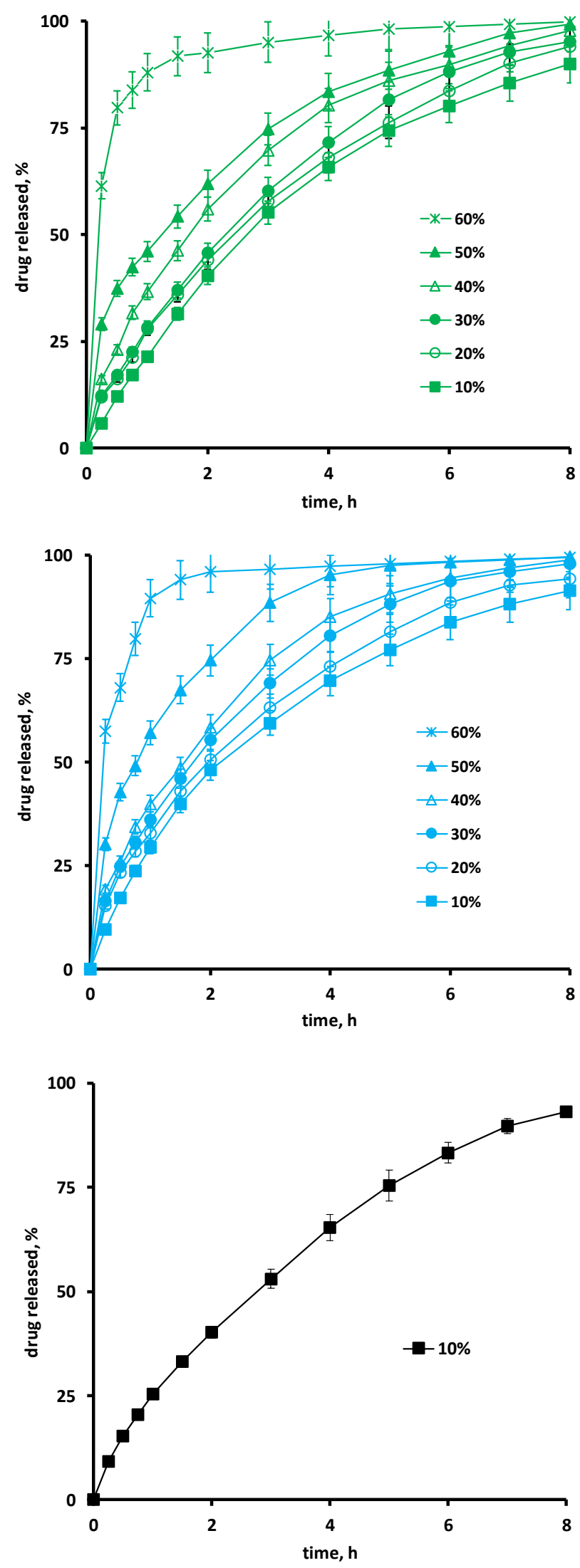

Figure 11 


\section{References}

[1] S. Kiortsis, K. Kachrimanis, T. Broussali, S. Malamataris, Drug release from tableted wet granulations comprising cellulosic (HPMC or HPC) and hydrophobic component, Eur. J. Pharm. Biopharm. 59 (2005) 73-83.

[2] F. Siepmann, K. Eckart, A. Maschke, K. Kolter, J. Siepmann, Modeling drug release from PVAc/PVP matrix tablets, J. Control. Release 141 (2010) 216-222.

[3] F. Tajarobi, S. Abrahmsén-Alami, A. Larsson, Dissolution rate enhancement of parabens in PEG solid dispersions and its influence on the release from hydrophilic matrix tablets, J. Pharm. Sc. 100 (2011) 275-283.

[4] E. Losi, N.A. Peppas, R.A. Ketcham, G. Colombo, R. Bettini, F. Sonvico1, P. Colombo, Investigation of the swelling behavior of Dome Matrix drug delivery modules by highresolution X-ray computed tomography, J. Drug Deliv. Sci. Technol. 23 (2013) 165-170.

[5] A.C.D. Recife, A.B. Meneguin, B.S.F. Cury, R.C. Evangelista, Evaluation of retrograded starch as excipient for controlled release matrix tablets, J. Drug Deliv. Sci. Technol. 40 (2017) 83-94.

[6] A.D.B. Martínez, M.V.M. Bellver, I.C.R. Galán, Matrix tablets based on amino acidderived polyesteramide containing release modifiers, J. Drug Deliv. Sci. Technol. 42 (2017) 307-314.

[7] J. Yin, W. Wang, X. Xu, H. Li, M. Cong, X. Zhao, C. Wang, Preparation, characterization and pharmacokinetics of extended-release tablets of marine polysaccharide drug, J. Drug Deliv. Sci. Technol. 43 (2018) 353-361.

[8] M.E. Campos-Aldrete, L. Villafuerte-Robles, Influence of the viscosity grade and the particle size of HPMC on metronidazole release from matrix tablets Eur. J. Pharm. Biopharm. 43 (1997) 173- 178. 
[9] G.S. Rekhi, R.V. Nellore, A.S. Hussain, LG. Tillman, H.J. Malinowski, L.L. Augsburger, Identification of critical formulation and processing variables for metoprolol tartrate extended-release (ER) matrix tablets, J. Control. Release 59 (1999) 327-342.

[10] S. Baumgartner, G. Lahajnar, A. Sepe, J. Kristl, Quantitative evaluation of polymer concentration profile during swelling of hydrophilic matrix tablets using $1 \mathrm{H}$ NMR and MRI methods, Eur. J. Pharm. Biopharm. 59 (2005) 299-306.

[11] S. Siepe, B. Lueckel, A. Kramer, A. Ries, R. Gurny, Strategies for the design of hydrophilic matrix tablets with controlled microenvironmental $\mathrm{pH}$, Int. J. Pharmaceut. 316 (2006) 14-20.

[12] R. Ali, A. Dashevsky, R Bodmeier, Poly vinyl acetate and ammonio methacrylate copolymer as unconventional polymer blends increase the mechanical robustness of HPMC matrix tablets, Int. J. Pharmaceut. 516 (2017) 3-8.

[13] V. Vanhoorne, L. Janssens, J. Vercruysse, T. De Beer, J.P. Remon, C. Vervaet, Continuous twin screw granulation of controlled release formulations with various HPMC grades, Int. J. Pharmaceut. 511 (2016) 1048-1057.

[14] V. De Simone, A. Dalmoro, G. Lamberti, D. Caccavo, M. d'Amore, A.A. Barba, HPMC granules by wet granulation process: Effect of vitamin load on physicochemical, mechanical and release properties, Carbohydr. Polym. 181 (2018) 939-947.

[15] G. Lamberti, I. Galdi, A.A. Barba, Controlled release from hydrogel-based solid matrices. A model accounting for water up-take, swelling and erosion, Int. J. Pharmaceut. 407 (2011) 78-86.

[16] G. Lamberti, S Cascone, M.M. Cafaro, G. Titomanlio, M. d'Amore, A.A. Barba, Measurements of water content in hydroxypropyl-methyl-cellulose based hydrogels via texture analysis, Carbohydr. Polym. 92 (2013) 765-768. 
[17] S. Cascone, G. Lamberti, G. Titomanlio, M. d'Amore, A.A. Barba, Measurements of nonuniform water content in hydroxypropyl-methyl-cellulose based matrices via texture analysis Carbohydr. Polym. 103 (2014) 348-354.

[18] J. Siepmann, H. Kranz, N.A. Peppas, R. Bodmeier, Calculation of the required size and shape of hydroxypropyl methylcellulose matrices to achieve desired drug release profiles. Int. J. Pharmaceut. 201 (2000) 151-164.

[19] J. Siepmann, N.A. Peppas, Modeling of drug release from delivery systems based on hydroxypropyl methylcellulose (HPMC), Adv. Drug Del. Rev. 48 (2001) 139-157.

[20] P. Borgquist, A. Körner, L. Piculell, A. Larsson, A. Axelsson, A model for the drug release from a polymer matrix tablet —effects of swelling and dissolution, J. Control. Release 113 (2006) 216-225.

[21] A.A. Barba, M. d'Amore, S. Cascone, S. Chirico, G. Lamberti, G. Titomanlio, On the Behavior of HPMC/Theophylline Matrices for Controlled Drug Delivery, J. Pharm. Sci. 98 (2009) 4100-4110.

[22] P. Gao, J.W. Skoug, P.R. Nixon, T.R. Ju, N.L. Stemm, K.C. Sung, Swelling of Hydroxypropyl Methylcellulose Matrix Tablets. 2. Mechanistic Study of the Influence of Formulation Variables on Matrix Performance and Drug Release, J. Pharm. Sci. 85 (1996) $732-740$.

[23] A.A. Barba, M, d'Amore, S. Chirico, G. Lamberti, S. Cascone, G. Lamberti, G. Titomanlio, Swelling of cellulose derivative (HPMC) matrix systems for drug delivery, Carbohydr. Polym. 78 (2009) 469-474.

[24] C.A. Fyfe, A.I. Blazek-Welsh, Quantitative NMR imaging study of the mechanism of drug release from swelling hydroxypropylmethylcellulose tablets, J. Control. Release 68 (2000) 313-333. 
[25] Y.Y. Chen, L.P. Hughes, L.F. Gladden, M.D. Mantle, Quantitative Ultra-Fast MRI of HPMC Swelling and Dissolution, J. Pharm. Sci. 99 (2010) 3462-3472.

[26] S. Yassin, K. Su, H. Lin, L.F. Gladden, J.A. Zeitler, Diffusion and swelling measurements in pharmaceutical powder compacts using terahertz pulsed imaging, J. Pharm. Sci. 104 (2015) 1658-1667.

[27] J. Siepmann, F. Siepmann, Mathematical modeling of drug delivery, Int. J. Pharmaceut. 364 (2008) 328-343.

[28] J. Siepmann, F. Siepmann, Modeling of diffusion controlled drug delivery, J. Control. Release 161 (2012) 351-362.

[29] E. Kaunisto, F. Tajarobi, S. Abrahmsen-Alami, A. Larsson, B. Nilsson, A. Axelsson, Mechanistic modelling of drug release from a polymer matrix using magnetic resonance microimaging, Eur. J. Pharm. Sci. 48 (2013) 698-708.

[30] J. Siepmann, A. Faham, S.D. Clas, B.J. Boyd, V. Jannin, A. Bernkop-Schnuerch, H. Zhao, S. Lecommandoux, J.C. Evans, C. Allen, O.M. Merkel, G. Costabile, M.R. Alexander, R.D. Wildman, C.J. Roberts, J.C. Leroux. Lipids and polymers in pharmaceutical technology: lifelong companions. Int. J. Pharmaceut. 558 (2019) 128 - 142.

[31] J. Siepmann, F. Siepmann, Mathematical modeling of drug dissolution, Int. J. Pharmaceut. 453 (2013) 12-24.

[32] F. Siepmann, Y. Karrout, M. Gehrke, F. Penz, J. Siepmann, Limited drug solubility can be decisive even for freely soluble drugs in highly swollen matrix tablets, Int. J. Pharmaceut. 526 (2017) 280-290.

[33] J. Siepmann, H. Kranz, R. Bodmeier, N.A. Peppas, HPMC-matrices for controlled drug delivery: A new model combining diffusion, swelling and dissolution mechanisms and predicting the release kinetics, Pharm. Res. 16 (1999) 1748-1756. 
[34] G. Lamberti, I. Galdi, A.A. Barba, Controlled release from hydrogel-based solid matrices. A model accounting for water up-take, swelling and erosion, Int. J. Pharmaceut. 407 (2011) 78-86.

[35] A. Viridén, B. Wittgren, A. Larsson, Investigation of critical polymer properties for polymer release and swelling of HPMC matrix tablets, Eur. J. Pharm. Sci. 36 (2009) 297309.

[36] A. Viridén, B. Wittgren, A. Larsson, The consequence of the chemical composition of HPMC in matrix tablets on the release behaviour of model drug substances having different solubility, Eur. J. Pharm. Biopharm. 77 (2011) 99-110.

[37] D. Caccavo, G. Lamberti, A.A. Barba, S. Abrahmsén-Alami, A. Viridén, A. Larsson, Effects of HPMC substituent pattern on water up-take, polymer and drug release: An experimental and modelling study, Int. J. Pharmaceut. 528 (2017) 705-713.

[38] F. Tajarobi, S. Abrahmsén-Alami, A.S. Carlsson, A. Larsson, Simultaneous probing of swelling, erosion and dissolution by NMR-microimaging-Effect of solubility of additives on HPMC matrix tablets, Eur. J. Pharm. Sci. 37 (2009) 89-97.

[39] L. Lamoudi, J.C. Chaumeil, K. Daoud, Swelling, erosion and drug release characteristics of sodium diclofenac from heterogeneous matrix tablets, J. Drug Deliv. Sci. Technol. 31 (2016) 93-100.

[40] J. Siepmann, Y. Karrout, M. Gehrke, F.K. Penz, F. Siepmann, Predicting drug release from HPMC/lactose tablets. Int. J. Pharmaceut. 441 (2013) 826-834.

[41] E. Kaunisto, M. Marucci, P. Borgquist, A. Axelsson, Mechanistic modelling of drug release from polymer-coated and swelling and dissolving polymer matrix systems, Int. J. Pharmaceut. 418 (2011) 54-77. 


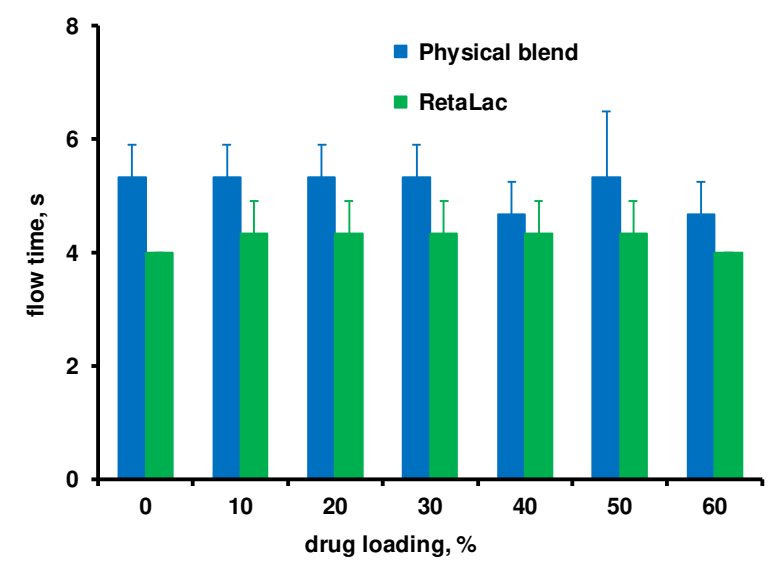

$0.1 \mathrm{M} \mathrm{HCl}$

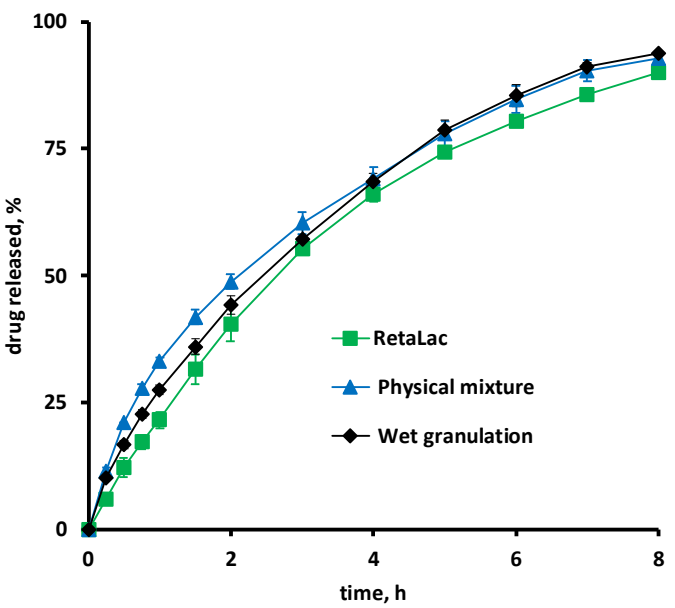

pH 7.4

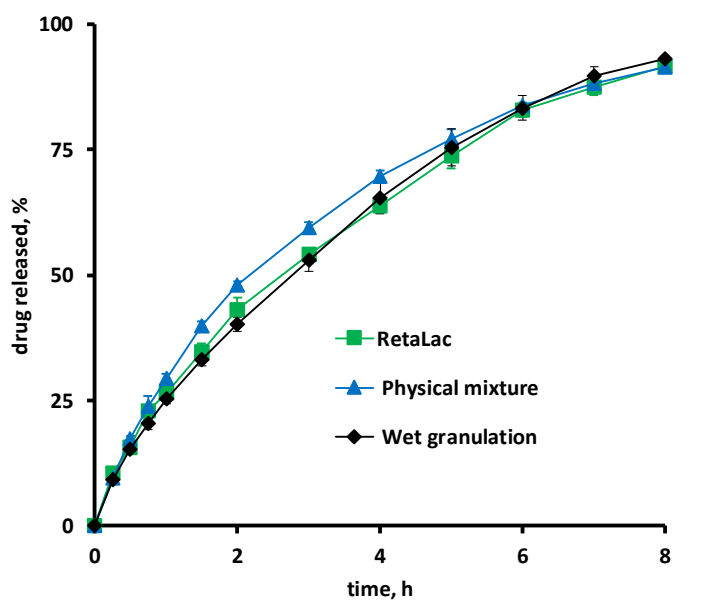

